\title{
Manipulation of Neural Precursors in situ: Induction of Neurogenesis in the Neocortex of Adult Mice
}

\author{
Sanjay S. Magavi and Jeffrey D. Macklis
}

Over the past three decades, research exploring potential neuronal replacement therapies have focused on replacing lost neurons by transplanting cells or grafting tissue into diseased regions of the brain (Bjorklund and Lindvall 2000). Over most of the past century of modern neuroscience, it was thought that the adult brain was completely incapable of generating new neurons. However, in the last decade, the development of new techniques has resulted in an explosion of new research showing that neurogenesis, the birth of new neurons, normally occurs in two limited and specific regions of the adult mammalian brain, and that there are significant numbers of multipotent neural precursors in many parts of the adult mammalian brain (Palmer et al. 1995). Recent findings from our lab demonstrate that it is possible to induce neurogenesis de novo in the adult mammalian brain, particularly in the neocortex where it does not normally occur, and that it may become possible to manipulate endogenous multipotent precursors in situ to replace lost or damaged neurons (Scharff et al. 2000; Magavi et al. 2000). Elucidation of the relevant molecular controls may allow the development of neuronal replacement therapies for neurodegenerative disease and other CNS injuries that do not require transplantation of exogenous cells.

[Neuropsychopharmacology 25:816-835, 2001] (C) 2001 American College of Neuropsychopharmacology. Published by Elsevier Science Inc.
KEY WORDS: Neural precursors; Stem cells; Neurogenesis; Brain repair; Neocortex; Cerebral cortex; Neural transplantation

Neural cell replacement therapies are based on the idea that neurological function lost to injury or neurodegenerative disease can be improved by introducing new cells that can replace the function of lost neurons. Theoretically, the new cells can do this in one of two general

From the Division of Neuroscience, Children's Hospital; Department of Neurology and Program in Neuroscience, Harvard Medical School (SSM, JDM), Boston, MA 02115

Address correspondence to: Jeffrey D. Macklis, Division of Neuroscience, Children's Hospital, Harvard Medical School, 320 Longwood Ave., Enders 354, Boston, MA 02115, Tel.: (617) 355-7185, Fax: (617) 734-1646, E-mail: jeffrey.macklis@tch.harvard.edu

Received July 18, 2001; revised August 8, 2001; accepted August 10, 2001. ways (Bjorklund and Lindvall 2000). New neurons can anatomically integrate into the host brain, becoming localized to the diseased portion of the brain, receiving afferents, expressing neurotransmitters, and forming axonal projections to relevant portions of the brain. Such neurons would function by integrating into the microcircuitry of the nervous system and replacing lost neuronal circuitry. Alternatively, newly introduced cells could more simply constitutively secrete neurotransmitters into local CNS tissue or they could be engineered to produce growth factors to support the survival or regeneration of existing neurons. Growing knowledge about the normal role of endogenous neural precursors, their potential differentiation fates, and their responsiveness to a variety of cellular and molecular controls suggest that neuronal replacement therapies based on manipulation of endogenous precursors either in situ or ex vivo may be possible. 
Neuronal replacement therapies based on the manipulation of endogenous precursors in situ may have advantages over transplantation-based approaches, but they may have several limitations as well. The most obvious advantage of manipulating endogenous precursors in situ is that there is no need for external sources of cells. Cells for transplantation are generally derived from embryonic tissue, non-human species (xenotransplantation), or cells grown in culture. Use of embryonic-derived tissue aimed toward human diseases is complicated by limitations in availability and by both political and ethical issues; e.g. current transplantation therapies for Parkinson's disease require tissue from several embryos. Xenotransplantation of animal cells carries potential risks of introducing novel diseases into humans, and questions about how well xenogenic cells will integrate into the human brain. In many cases, cultured cells need to be immortalized by oncogenesis, increasing the risk that the cells may become tumorigenic. In addition, transplantation of cells from many of these sources risk immune rejection and may require immunosuppression, if they are not derived from the recipient.

However, there are also potential limitations to the potential of manipulating endogenous precursor cells as a neuronal replacement therapy. First, such an approach may be practically limited to particular regions of the brain, since multipotent neural precursors are densely distributed only in particular subregions of the adult brain (e.g. the subventricular zone, SVZ, and hippocampal subgranular zone). In some cases, it is possible that there simply may not be sufficient precursor cells to effect functional recovery. In addition, the potential differentiation fates of endogenous precursors may be too limited to allow their integration into varied portions of the brain. Another potential difficulty is that it may be difficult to provide the precise combination and sequence of molecular signals necessary to induce endogenous precursors to efficiently and precisely proliferate and differentiate into appropriate types of neurons deep in the brain.

The substantial amount of prior research regarding constitutively occurring neurogenesis provides insight into the potential and limitations of for endogenous precursor based neuronal replacement therapies. Recent work has partially elucidated the normal behavior of endogenous adult precursors, including their ability to migrate to select brain regions, differentiate into neurons, integrate into normal neural circuitry, and, finally, functionally integrate into the adult brain. Research is also beginning to elucidate biochemical and behavioral controls over constitutively occurring neurogenesis. The location, identity, and differentiation potential of endogenous adult precursors are beginning to be understood. In this review, we will first review research from a variety of labs regarding normally occurring neurogenesis, then review some of our experiments demonstrating that endogenous neural precursors can be induced to differentiate into neurons in regions of the adult brain that do not normally undergo neurogenesis.

\section{CONSTITUTIVELY-OCCURRING ADULT MAMMALIAN NEUROGENESIS}

Ramón y Cajal (1913-1914) has been widely quoted as writing: "In the adult centers the nerve paths are something fixed, ended and immutable. Everything may die, nothing may be regenerated." The relative lack of recovery from CNS injury and neurodegenerative disease and the relatively subtle and extremely limited distribution of neurogenesis in the adult mammalian brain resulted in the entire field reaching the conclusion that neurogenesis does not occur in the adult mammalian brain. Joseph Altman was the first to use techniques sensitive enough to detect the ongoing cell division that occurs in adult brain. Using tritiated thymidine as a mitotic label, he published evidence that neurogenesis constitutively occurs in the hippocampus (Altman and Das 1965) and olfactory bulb (Altman 1969) of the adult mammalian brain. These results were later replicated using tritiated thymidine labeling followed by electron microcopy (Kaplan 1981). However, the absence of neuron-specific immunocytochemical markers at the time resulted in identification of putatively newborn neurons being made on purely morphological criteria. These limitations led to a widespread lack of acceptance of these results, and made research in the field difficult.

The field of adult neurogenesis was rekindled in 1992, when Reynolds and Weiss showed that precursor cells isolated from the forebrain (Reynolds and Weiss 1992) can differentiate into neurons in vitro. These results, and technical advances, including the development of immunocytochemical reagents that could more easily and accurately identify the phenotype of various neural cells, led to an explosion of research in the field. Normally occurring neurogenesis in the olfactory bulb, olfactory epithelium, and hippocampus have now been well-characterized in the adult mammalian brain.

\section{OLFACTORY BULB NEUROGENESIS}

The cells contributing to olfactory bulb neurogenesis originate in the anterior peri-ventricular zone, and thus undergo a fascinating and intricate path of migration to reach their final position in the olfactory bulb. Adult olfactory bulb neurogenesis has been most extensively studied in the rodent, though there is in vitro (Pincus et al. 1998; Kirschenbaum et al. 1994) and in vivo (Bernier et al. 2000) evidence suggesting that such neuronal precursors exist in humans. Several experiments show that the precursors that contribute to olfactory bulb neurogenesis reside in the anterior portion of the subventric- 
ular zone. When retroviruses (Lois and Alvarez-Buylla 1994), tritiated thymidine (Lois and Alvarez-Buylla 1994), vital dyes (Lois and Alvarez-Buylla 1994; Doetsch and Alvarez-Buylla 1996), or virally labeled SVZ cells (Doetsch and Alvarez-Buylla 1996; Luskin and Boone 1994) are microinjected into the anterior portion of the SVZ of postnatal animals, labeled cells are eventually found in the olfactory bulb. Upon reaching the olfactory bulb, these labeled neurons differentiate into interneurons specific to the olfactory bulb, olfactory granule cells and peri-glomerular cells. To reach the olfactory bulb, the neuroblasts undergo tangential chain migration though the rostral migratory stream (RMS) into the olfactory bulb (Rousselot et al. 1995). Once in the olfactory bulb, the neurons migrate along radial glia away from the RMS and differentiate into interneurons.

Of considerable interest have been the factors that contribute to the direction of migration of the neuroblasts, as well as factors involved in initiating and controlling migration itself. In vitro experiments show that caudal septum explants secrete a diffusible factor, possibly the molecule Slit (Mason et al. 2001) that repels olfactory bulb neural precursors (Hu and Rutishauser 1996). Consistent with the idea that SVZ precursor migration is directed by repulsion is the finding that $S V Z$ precursors migrate anteriorly along the RMS even in the absence of the olfactory bulb (Kirschenbaum et al. 1999). The tangential migration of the cells seems to be at least partially mediated by PSA-NCAM, expressed by the neuroblasts themselves (Hu et al. 1996). This may be modified by tenascin and chondroitin sulfate proteoglycans that are located near the SVZ (Gates et al. 1995). Neuroblasts undergoing chain migration along the RMS do not travel along radial glia, although glia may play a role in their migration. Garcia-Verdugo et al. presented anatomical evidence that SVZ neuroblasts migrate within sheaths of slowly dividing astrocytes (Garcia-Verdugo et al. 1998). However, the astrocyte sheaths may not be necessary for tangential migration, since a great deal of tangential migration occurs in the first postnatal week, before astrocytes can be found in the RMS (Law et al. 1999). Understanding the factors that contribute to normal SVZ precursor migration could be important in developing approaches to induce such precursors to migrate to injured or degenerating regions of the brain.

The effort to identify the neural precursors that contribute to olfactory bulb neurogenesis has generated a great deal of controversy. Two potential sources of olfactory bulb neuroblasts have been suggested: astrocytes in the subventricular zone, and ependymal cells lining the ventricles. It has been reported that single ependymal cells are capable of producing neurospheres (Johansson et al. 1999), free-floating spheres of cultured multipotent neural precursors, neurons, and glia. In contrast, it has also been reported that ciliary ependymal cells form spheres that consist of only astrocytes (Chiasson et al.
1999). Other investigators have been unable to generate neurospheres from single ciliary ependymal cells, and, instead, suggest that the multipotent neural precursors found in the adult brain are a type of astrocyte, expressing astrocytic morphology and glial fibrillary acidic protein (GFAP) (Doetsch et al. 1999). Another independent report provides support for the concept that multipotent neural precursors with similarities to astrocytes contribute to adult neurogenesis (Laywell et al. 2000). While the majority of currently available evidence suggests that GFAP-expressing cells in the SVZ are the source of olfactory bulb neurogenesis, it is important to distinguish between true astroglia and a distinct class of precursor cells that may also express GFAP. GFAP, while generally a reliable marker for activated astrocytes, has been used as a sole phenotypic marker in reports suggesting that astrocytes are multipotent neural precursors, or stem cells. It is quite possible that at least some multipotent neural precursors may also express GFAP, while remaining distinct from astroglia. Further clarifying the identity of potentially multiple classes of multipotent neural precursors that contribute to adult neurogenesis will increase our ability to manipulate such cells.

Although the identity of the adult multipotent neural precursors in the SVZ is still controversial, a number of experiments have been performed to manipulate their fate and examine their potential, both in vitro and in vivo. These results will guide attempts to manipulate endogenous precursors for brain repair. In vitro, subventricular zone precursors have been exposed to a number of factors to determine their responses. Generally, precursor cells have been removed from the brain, dissociated, and cultured in epidermal growth factor (EGF) and/or basic fibroblast growth factor (bFGF). The EGF and/or bFGF is then removed, and the cells are exposed to growth factors of interest. The details of this process, including the particular regions the cells are derived from, the media they are plated in, and the substrate they are plated on, can have significant effects on the fate of the precursors (Whittemore et al. 1999). EGF and bFGF (Gritti et al. 1995, 1996, 1999) both induce the proliferation of subventricular zone precursors, and can influence their differentiation. EGF tends to direct cells to a glial fate, and bFGF more toward neuronal fate (Whittemore et al. 1999). BMPs promote differentiation of SVZ precursors into astroglial fates (Gross et al. 1996), while platelet-derived growth factor (PDGF) (Whittemore et al. 1999; Williams et al. 1997) and insulinlike growth factor-I (IGF-I) (Arsenijevic and Weiss 1998) promote SVZ precursors to differentiate into neurons. There are conflicting results regarding whether brainderived neurotrophic factor (BDNF) promotes the survival (Kirschenbaum and Goldman 1995; Goldman et al. 1997) or differentiation (Arsenijevic and Weiss 1998; Ahmed et al. 1995) of SVZ precursors in vitro (Ahmed et al. 1995). In vitro results show that it may be possible to influence the proliferation and differentiation of adult SVZ precursors. 
The effects of several growth factors have also been tested in vivo, to investigate their effects under physiological conditions. Intracerebroventricularly (ICV) infused EGF or TGF- $\alpha$ induce a dramatic increase in SVZ precursor proliferation, and bFGF induces a smaller increase in proliferation (Craig et al. 1996; Kuhn et al. 1997). Even subcutaneously delivered bFGF can induce the proliferation of SVZ precursors in adult animals (Wagner et al. 1999). But despite the fact that newborn mitogen-induced cells disperse into regions of the brain surrounding the ventricles, it is generally accepted that none of the newborn cells differentiate into neurons (Kuhn et al. 1997). Intraventricularly infused BDNF increased the number of newly born neurons found in the olfactory bulbs of adult animals (Zigova et al. 1998). These results extend the in vitro results, and suggest that it may be possible to use growth factors to manipulate adult endogenous precursors in vivo for brain repair.

Several reports have attempted to establish the differentiation potential of SVZ multipotent precursors, but these have yielded conflicting results. Postnatal mouse SVZ precursors can differentiate into neurons in a number of regions in the developing neuraxis (Lim et al. 1997), while their fate is more limited to astroglia when they are transplanted into adult brain (Herrera et al. 1999). Adult mouse SVZ precursors injected intravenously into sublethally irradiated mice have been reported to differentiate into hematopoetic cells, interpreted as demonstrating the broad potential of neural precursors for differentiation and interlineage "trans-differentiation." However, it is possible that a chance transformation of cultured SVZ cells led to a single transformant precursor accounting for this finding. In this event, it could be concluded that this result is not generally the case. However, labeled multipotent neural precursors derived from adult mouse and transplanted into stage 4 chick embryos or developing mouse morulae or blastocysts, can integrate into the heart, liver, and intestine, and express proteins specific for each of these sites (Clarke et al. 2000). Adult multipotent neural precursors may not be totipotent, but they appear to be capable of differentiating into a wide variety of cell types under appropriate conditions. These results indicate that the local cellular and molecular environment in which SVZ neural precursors are located can play a significant role in their differentiation. Providing the cellular and molecular signals for appropriate differentiation and integration of new neurons will be critical for neuronal replacement therapies in which endogenous neural precursors are either transplanted or manipulated in situ.

\section{OLFACTORY EPITHELIUM NEUROGENESIS}

Sensory neurons in the olfactory epithelium are continually generated in adult rodents. The globose basal cells of the olfactory epithelium divide, differentiate into neurons, and send their axons through the olfactory nerve to the olfactory bulb (Huard and Schwob 1995; Caggiano et al. 1994). Of all the neurons in the mammalian body, olfactory epithelium sensory neurons are most directly exposed to potentially damaging influences, interpreted as necessitating their continual replacement. The constant flow of air over the epithelium brings a continuously varying combination of new odorants and potential insults to the olfactory sensory neurons. Despite the precarious position of olfactory receptor neurons, the population of olfactory receptor neurons is maintained, and mammals maintain a fairly consistent sense of smell throughout life.

Neurogenesis in the olfactory epithelium is strongly modulated by neuronal death in the epithelium. Olfactory nerve lesions or olfactory bulb lesions, which lead to the degeneration of axotomized neurons (Graziadei and Graziadei 1979; Carr and Farbman 1992), result in an increase in proliferation of precursors (Caggiano et al. 1994; Graziadei and Graziadei 1979; Carr and Farbman 1992; Calof et al. 1996; Samanen and Forbes 1984). The new neurons that form in the adult olfactory epithelium send axons through the olfactory nerve and into the mature olfactory bulb (Barber 1982; Crews and Hunter 1994). The ability of the newborn neurons to reform long-distance projections is probably due to both their immature state and the environment through which they extend their axons.

In vitro experiments suggest that mature olfactory sensory neurons produce a signal that inhibits neurogenesis. Olfactory epithelial precursor cells undergo dramatically reduced neurogenesis in the presence of mature olfactory receptor neurons in vitro, (Calof et al. 1998), suggesting that when olfactory sensory neurons are lost in vivo, the factors inhibiting neurogenesis are reduced, allowing the formation of new sensory neurons. Understanding the signals that inhibit neurogenesis and neuronal integration may be as important as understanding the signals that foster neurogenesis.

However, the factors that inhibit neurogenesis in the adult olfactory epithelium have not yet been discovered, and research in the field has focused on many of the growth factors that influence neurogenesis in the SVZ and olfactory bulb. Many of the same factors influence both olfactory bulb and olfactory epithelial neurogenesis. IGF-I increases the rate of neurogenesis of olfactory epithelium precursors, both in vivo and in vitro (Pixley et al. 1998). In vitro, FGF-2 stimulates the proliferation of globose basal cells, TGF-a induces their differentiation, and PDGF promotes their survival (Newman et al. 2000).

Research in the olfactory epithelium highlights the role of inhibitory factors in controlling neurogenesis; understanding these signals in degenerating portions of the brain may be instrumental in developing neuronal replacement therapies. 


\section{HIPPOCAMPAL NEUROGENESIS}

Neurogenesis in the adult hippocampus has been extensively studied, due at least partially to the tantalizing connection between the hippocampus and the formation of memory. Does hippocampal neurogenesis play a part in memory formation? This question has only begun to be answered, but our understanding of hippocampal neurogenesis is already quite significant. Of particular interest is the fact that hippocampal neurogenesis can be modulated by physiological and behavioral events such as aging, stress, seizures, learning, and exercise. These properties of hippocampal neurogenesis may provide novel methods of studying neurogenesis and may elucidate broader influences that may be relevant to neuronal replacement therapies.

Hippocampal neurogenesis has been described in vivo in adult rodents (Altman and Das 1965), monkeys (Gould et al. 1998, 1999b; Kornack and Rakic 1999) and adult humans (Eriksson et al. 1998). Newborn cells destined to become neurons are generated along the innermost aspect of the granule cell layer, the subgranular zone, of the dentate gyrus of the adult hippocampus. The cells migrate a short distance into the granule cell layer, send dendrites into the molecular layer of the hippocampus, and send their axons into the $\mathrm{CA} 3$ region of the hippocampus (Stanfield and Trice 1988; Markakis and Gage 1999; Hastings and Gould 1999). Adult-born hippocampal granule neurons are morphologically indistinguishable from surrounding granule neurons (Gage et al. 1998). The precursor cells appear to mature rapidly, and they extend their processes into the CA3 region as early as four days after division (Hastings and Gould 1999). The properties of both the precursor cells and the hippocampal environment likely contribute to the rapid maturation observed.

Much research on hippocampal precursors has been performed in vivo, but many in vitro results are also useful for understanding the effects of growth factors on the differentiation of hippocampal precursors. Hippocampal precursors cells are studied in vitro much like SVZ precursors: they are removed from the brain, dissociated, and typically cultured in either EGF or bFGF; the mitogen is then removed; and the cells are exposed to the growth factors of interest. Hippocampal precursors proliferate in response to FGF-2 and can differentiate into astroglia, oligodendroglia, and neurons in vitro (Gage et al. 1998). BDNF increases both neuronal survival and differentiation, while NT-3, NT-4/5, and CNTF have more limited effects (Lowenstein and Arsenault 1996). Further demonstrating the existence of precursors in the adult human, multipotent precursors derived from the adult human brain can be cultured in vitro (Kukekov et al. 1999; Roy et al. 2000).

Hippocampal neurogenesis occurs throughout adulthood, but declines with age (Kuhn et al. 1996). This age- related decline could be due to a depletion of multipotent precursors with time, a change in precursor cell properties, or a change in the levels of molecular factors that influence neurogenesis. Understanding what causes this age-related decrease in neurogenesis may be important in assessing the potential utility of potential future neuronal replacement therapies based in manipulation of endogenous precursors. Although aged rats have dramatically lower levels of neurogenesis than young rats, adrenalectomized aged rats have levels of neurogenesis very similar to those of young adrenalectomized rats (Cameron and McKay 1999; Montaron et al. 1999). These results suggest that it is at least partially increased corticosteroids, which are produced by the adrenal glands, and not a decrease in the number of multipotent precursors, that leads to age-related decreases in neurogenesis. At least in the hippocampus, multipotent precursors survive with advancing age.

Seizures can also increase hippocampal neurogenesis. However, it appears that seizure-induced neurogenesis may contribute to inappropriate plasticity, highlighting the fact that newly introduced neurons need to be appropriately integrated into the brain in order to have beneficial effects. Chemically or electrically induced seizures induce the proliferation of subgranular zone precursors, the majority of which differentiate into neurons in the granule cell layer (Bengzon et al. 1997; Parent et al. 1997). However, some newborn cells differentiate into granule cell neurons in ectopic locations in the hilus or molecular layers of the hippocampus and form aberrant connections to the inner molecular layer of the dentate gyrus, in addition to the CA3 pyramidal cell region (Parent et al. 1997; Huang et al. 1999). It is hypothesized that these ectopic cells and aberrant connections may contribute to hippocampal kindling (Parent et al. 1998; Represa et al. 1995).

Hippocampal cell death or activity-related signals resulting from seizures may modify signals that lead to increased neurogenesis. Induced seizures lead to degeneration of hippocampal neurons (Magloczky and Freund 1993; Pollard et al. 1994; Whittington et al. 1989), which is followed by neurogenesis (Bengzon et al. 1997; Parent et al. 1997). Excitotoxic or physical lesions of the hippocampal granule cell layer induce precursor cell proliferation within the dentate gyrus and the formation of neurons that have the morphological and immunocytochemical properties of granule cell neurons (Gould and Tanapat 1997). These results suggest that hippocampal granule cells either inhibit neurogenesis, as do neurons in the olfactory epithelium, or that they or surrounding cells produce signals that induce neurogenesis as they die. However, since neurogenesis is also increased by less pathological levels of electrophysiological activity (Derrick et al. 2000), it is also possible that signals induced by electrophysiological activity play a role in seizure-induced hippocampal neurogenesis. 
Events occurring in the hippocampus dramatically demonstrate that behavior and environment can have a quite direct influence on the brain's microcircuitry. Animals living in an enriched environment containing toys, running wheels, and social stimulation contain more newborn cells in their hippocampus than control mice living in standard cages (Kempermann et al. 1997). Experiments to further assess which aspects of the enriched environment contribute to increased neurogenesis reveal that a large portion of the increase can be attributed to simply exercise via running (van Praag et al. 1999a,b). Associative learning tasks that involve the hippocampus also appear to increase neurogenesis (Gould et al. 1999a). Stress, on the other hand, can reduce neurogenesis in both rodents (Gould et al. 1997, Tanapat et al. 1998) and primates (Gould et al. 1998). An intriguing, but completely speculative, idea that has been advanced by some in this field is that the processes mediating these effects on neurogenesis may underlie some of the benefits that physical and social therapies provide for patients with stroke and brain injury.

Some of the molecular mechanisms that mediate behavioral influences on hippocampal neurogenesis have begun to be elucidated. For instance, IGF-I, which increases adult hippocampal neurogenesis (Aberg et al. 2000), is preferentially transported into the brain in animals that are allowed to exercise. Blocking IGF-I activity in exercising animals reduces hippocampal neurogenesis, suggesting that IGF-I at least partially mediates the effects of exercise on neurogenesis (Trejo et al. 2001). Stress increases systemic adrenal steroid levels and reduces hippocampal neurogenesis (Tanapat et al. 1998). Adrenalectomy, which reduces adrenal steroids, including corticosteroids, increases hippocampal neurogenesis (Cameron and McKay 1999; Gould et al. 1992), suggesting that adrenal hormones at least partially mediate the effects of stress on hippocampal neurogenesis. Intriguingly, some antidepressant medications also appear to increase neurogenesis (Chen et al. 2000; Malberg et al. 2000). Together, these results demonstrate that adult neurogenesis can be modified by systemic signals, suggesting that modifying such systemic signals, and not only local ones, may be useful in developing potential future neuronal replacement therapies involving manipulation of endogenous precursors (Kempermann et al. 2000).

Adult hippocampal multipotent precursors can adopt a variety of fates in vivo, suggesting that they may be able to appropriately integrate into neuronal microcircuitry outside of the dentate gyrus of the hippocampus. Hippocampal precursors transplanted into to neurogenic regions of the brain can differentiate into neurons, while precursors transplanted into non-neurogenic regions do not differentiate into neurons at all. Adult rat hippocampal precursors transplanted into the rostral migratory stream migrate to the olfactory bulb and differentiate into a neuronal subtype not found in the hippocampus, tyrosine-hydroxylase-positive neurons (Suhonen et al. 1996). However, although adult hippocampal precursors transplanted into the retina can adopt neuronal fates and extend neurites, they do not differentiate into photoreceptors, demonstrating at least conditional limitation of their differentiation fate potential (Young et al. 2000; Nishida et al. 2000). These findings demonstrate the importance of the local cellular and molecular microenvironment in determining the fate of multipotent precursors. These results also highlight that, although adult hippocampal precursors can adopt a variety of neuronal fates, they may not be able to adopt every neuronal fate.

Some recent correlative evidence suggests that newly generated neurons in the adult hippocampus may participate in some way in hippocampal-dependent memory. Non-specifically inhibiting hippocampal neurogenesis using a systemic mitotic toxin impairs trace conditioning in a manner not seen in relevant controls, suggesting a role for newly born neurons in the formation of memories (Shors et al. 2001). These results, though correlative so far, suggest that adult-born hippocampal neurons integrate functionally into the adult mammalian brain. Ongoing research in multiple laboratories is exploring the precise role they play in the adult hippocampal circuitry.

An interesting, but as yet unproven, hypothesis concerning the role of hippocampal neurogenesis in human depression has been proposed. Jacobs et al. propose that insufficient hippocampal neurogenesis causally underlies depression (Jacobs et al. 2000). Consistent with this hypothesis, stress-related glucocorticoids are associated with a decrease in neurogenesis, and increased serotonin levels (Jacobs et al. 2000; Brezun and Daszuta 1999), or anti-depressants (Malberg et al. 2000) are associated with an increase in neurogenesis. However, the hippocampus is generally thought to be involved in memory consolidation, and less involved in the generation of mood, suggesting that altered hippocampal neurogenesis may be secondary to depression, rather than causative. This subject is reviewed in more depth in a review by Duman and colleagues in this issue (Duman et al. 2001).

\section{CORTICAL NEUROGENESIS}

The vast majority of studies investigating potential neurogenesis in the neocortex of the well-studied rodent brain do not report normally occurring adult cortical neurogenesis. Our own results demonstrate a complete absence of constitutively occurring neurogenesis in murine neocortex (Magavi et al. 2000). However, two studies reported low level, constitutively-occurring neurogenesis in specific regions of the neocortex of adult primates (Gould et al. 1999c) and in the visual cortex of 
adult rat (Kaplan 1981). In Gould et al., neurogenesis of 2-3 new neurons $/ \mathrm{mm}^{3}$ was reported in prefrontal, inferior temporal, and posterior parietal cortex of the adult macaque, but not in striate cortex, a presumably simpler primary sensory area. It appears that other groups have not yet been able to reproduce these findings in rodents or primates. There exists a single report of neurogenesis in the visual cortex of the adult rat (Kaplan 1981), but this study used tritiated thymidine and purely morphological cell type identification, and has not been confirmed by any other group, including our own. It is unclear whether neurogenesis occurs normally in the neocortex of any mammals, but further examination of potential constitutively-occurring neurogenesis in classically non-neurogenic regions will be required to definitively assess the potential existence of perhaps extremely low level neurogenesis.

\section{FUNCTIONAL ADULT NEUROGENESIS OCCURS IN NON-MAMMALIAN VERTEBRATES}

Functional adult neurogenesis also occurs in many nonmammalian vertebrates. The medial cerebral cortex of lizards, which resembles the dentate gyrus of mammals, undergoes postnatal neurogenesis and can regenerate in response to injury (Lopez-Garcia et al. 1992). Newts can regenerate their tails, limbs, jaws, and ocular tissues, and the neurons that occupy these regions (Jones and Corwin 1993; Brockes 1997). Goldfish undergo retinal neurogenesis throughout life (Johns and Easter 1977) and, impressively, can regenerate surgically excised portions of their retina in adulthood (Hitchcock et al. 1992). Although lower animals can undergo quite dramatic regeneration of neural tissue, it is unclear how relevant this is to mammals. It is thought that selective evolutionary pressures have led mammals to lose such abilities during normal life.

Birds, complex vertebrates whose brains are much closer to mammals in complexity, also undergo postnatal neurogenesis. Lesioned postnatal avian retina undergoes some neurogenesis, with the new neurons most likely arising from Muller glia (Fischer and Rey 2001). In songbirds, new neurons are constantly added to the high vocal center (Nottebohm 1985; Alvarez-Buylla et al. 1990), a portion of the brain necessary for the production of learned song (Nottebohm et al. 1976; Simpson and Vicario 1990; Williams et al. 1992), as well as to specific regions elsewhere in the brain, (but not all neuronal populations). It is possible to experimentally manipulate the extent to which new neurons are produced in at least one songbird, the zebrafinch, which does not normally seasonally replace HVC-RA projection neurons in the song production network, e.g. as canaries do (Scharff et al. 2000). Inducing cell death of HVC-RA neurons in zebra finches leads to deterioration in song. Neurogenesis increases following induced cell death and birds variably recover their ability to produce song coincident with the formation of new projections from area HVC to area RA, suggesting that induced neuronal replacement can restore a learned behavior.

\section{THE LOCATION OF ADULT MAMMALIAN MULTIPOTENT PRECURSORS}

If adult multipotent precursors were limited to the two neurogenic regions of the brain, the olfactory bulb and hippocampal dentate gyrus, it would severely limit the potential of neuronal replacement therapies based on in situ manipulation of endogenous precursors. However, adult multipotent precursors are not limited to the olfactory epithelium, anterior SVZ, and hippocampus of the adult brain; they have been cultured in vitro from caudal portions of the SVZ, septum (Palmer et al. 1995), striatum (Palmer et al. 1995), cortex (Palmer et al. 1999), optic nerve (Weiss et al. 1996), spinal cord (Weiss et al. 1996; Shihabuddin et al. 1997), and retina (Tropepe et al. 2000). The precursors derived from all these regions can self-renew and differentiate into neurons, astroglia, and oligodendroglia in vitro. It is thought that they normally differentiate only into glia or die in vivo. Cells from each region have different requirements for their proliferation and differentiation. Precursors derived from septum, striatum, cortex, and optic nerve are reported to require bFGF to proliferate and differentiate into neurons in vitro. There are conflicting reports on whether bFGF is sufficient to culture spinal cord precursors (Weiss et al. 1996; Shihabuddin et al. 1997). Retinal precursors do not require any mitogens in order to divide in vitro, though they do respond to both EGF and bFGF. As with all primary cultures, the particular details of the protocols used can strongly influence the proliferation, differentiation, and viability of the cultured cells, so it is difficult to compare results from different labs. It is estimated that adult multipotent precursors can be found in small but significant number in various regions of the brain; e.g. separating cortical neuronal precursors by Percoll gradient yields about 140 multipotent precursors per mg, vs. 200 per mg in the hippocampus (Palmer et al. 1999). Understanding the similarities and differences between the properties of multipotent precursors derived from different regions of the brain will be instrumental in potential developing neuronal replacement therapies based on manipulation of endogenous precursors.

Though it is not generally accepted, there are reports that, in addition to the undifferentiated multipotent precursors that are found in various portions of the brain, mature neurons themselves can be induced to divide (Brewer 1999; Gu et al. 2000). While it seems unlikely that a neuron could maintain the elaborate neurochemical and morphologic differentiation state of a 
mature neuron while replicating its DNA and remodeling its nucleus and soma, it is still theoretically possible. Though it is generally accepted that other neural cells, such as astroglia, can divide, most reports suggest that any attempt by differentiated neurons to re-enter the cell cycle results in aborted cycling and ultimately, death (Yang et al. 2001). Significant evidence will need to be presented to convincingly demonstrate that mature neurons in the adult brain are capable of mitosis.

\section{MANIPULATING THE CORTICAL ENVIRONMENT}

Endogenous multipotent precursors in the adult brain can divide, migrate, differentiate into neurons, receive afferents, and extend axons to their targets. Multipotent precursors are concentrated in the olfactory epithelium, anterior SVZ, and the dentate gyrus of the hippocampus, but they can be found in lower densities in a number of other regions of the adult brain. In addition, these precursors also have the a broad potential; they can differentiate into at least three different cell types, astroglia, oligodendroglia, and neurons, given an appropriate in vitro or in vivo environment. These properties of endogenous multipotent precursors led us to explore the fate of these precursors in an adult cortical environment that has been manipulated to support neurogenesis.

Our lab has previously shown that cortex undergoing synchronous degeneration of apoptotic projection neurons forms an instructive environment that can guide the differentiation of transplanted immature neurons or neural precursors. Immature neurons or multipotent neural precursors transplanted into targeted cortex migrate selectively to layers of cortex undergoing degeneration of projection neurons (Macklis 1993; Sheen and Macklis 1995; Hernit-Grant and Macklis 1996), differentiate into projection neurons (Macklis 1993; Sheen and Macklis 1995; Hernit-Grant and Macklis 1996; Snyder et al. 1997), receive afferent synapses (Macklis 1993; Snyder et al. 1997), express appropriate neurotransmitters and receptors, and re-form appropriate long-distance connections to the original contralateral targets of the degenerating neurons (Hernit-Grant and Macklis 1996) in adult murine neocortex. Immature neurons or neural precursors transplanted into control intact or kainic acid-lesioned cortex do not migrate, differentiate into projection neurons, or integrate into cortex. Together, these results suggested to us that cortex undergoing targeted apoptotic degeneration could direct endogenous multipotent precursors to integrate into adult cortical microcircuitry. But before discussing the fate of endogenous precursors in such an environment, we will review in more detail the results indicating that neocortex undergoing targeted apoptosis forms an instructive environment for neurogenesis.
Biophysically targeted apoptotic neurodegeneration produces highly specific cell death of selected projection neurons within defined regions of neocortex (Figure 1). Importantly, surrounding glia, interneurons, and projection neurons that have not been targeted are not injured by this approach (Macklis 1993; Madison and Macklis 1993). Degeneration results from the photoactivation of retrogradely transported nanospheres carrying the chromophore chlorin $e_{6}$, (Macklis 1993; Sheen and Macklis 1994, 1995). First, nanospheres carrying the chromophore chlorin $e_{6}$ are injected into the axonal terminal fields of the targeted projection neurons. The nanospheres are retrogradely transported to the soma of the projection neurons and stored non-toxically within neuronal lysosomes. The projection neurons are then noninvasively exposed to long wavelength light through intact dura and/or skull, which specifically induces the chlorin $e_{6}$ to produce singlet oxygen, and induces apoptosis of chlorin $e_{6}$ containing cells. Chlorin $e_{6}$ only produces the reactive oxygen species when excited by near-infrared light. The long wavelength light used is not absorbed by neural tissue and does not cause damage by either heating or radiation-based effects. Since neither the chlorin $e_{6}$ nor the long wavelength light cause degeneration by themselves, only neurons both selectively labeled with the chromophore and located in the controlled light path undergo apoptotic degeneration.

We have applied this approach in several mammalian and avian CNS systems, effecting 50\% to $99 \%$ degeneration (typically $\sim 70 \%$ ) of the targeted populations (Scharff et al. 2000; Magavi et al. 2000; Macklis 1993; Sheen and Macklis 1995). In neocortex, we have produced selective degeneration of pyramidal neurons with callosal projections (laminae 2/3 and/or 5 neurons) or cortico-thalamic projections (Magavi et al. 2000; Macklis 1993; Sheen and Macklis 1995; Madison and Macklis 1993). Targeted neurons die by apoptosis, via a cascade of characteristic apoptotic cellular events. Targeted neurons undergo nuclear and internucleosomal DNA fragmentation, undergo heterochromatin condensation, and form apoptotic bodies (Sheen and Macklis 1994; Sheen et al. 1992). Targeted neurons are TdT-mediated dUTP nick-end labeling (TUNEL) positive and are phagocytically removed from the brain without inflammation or gliosis. Neuronal death depends on both new protein synthesis and intrinsic endonuclease activity. This relatively synchronous initiation of neuronal apoptosis leads to prolonged alterations in gene expression (Wang et al. 1998), that may not be induced by the relatively sporadic cell death that occurs in neurodegenerative disease.

The instructive environment that exists in apoptotically degenerating cortex can alter the differentiation fate of transplanted immature neurons or multipotent precursors. To examine the fate of heterotopically transplanted immature neurons in cortex undergoing apop- 


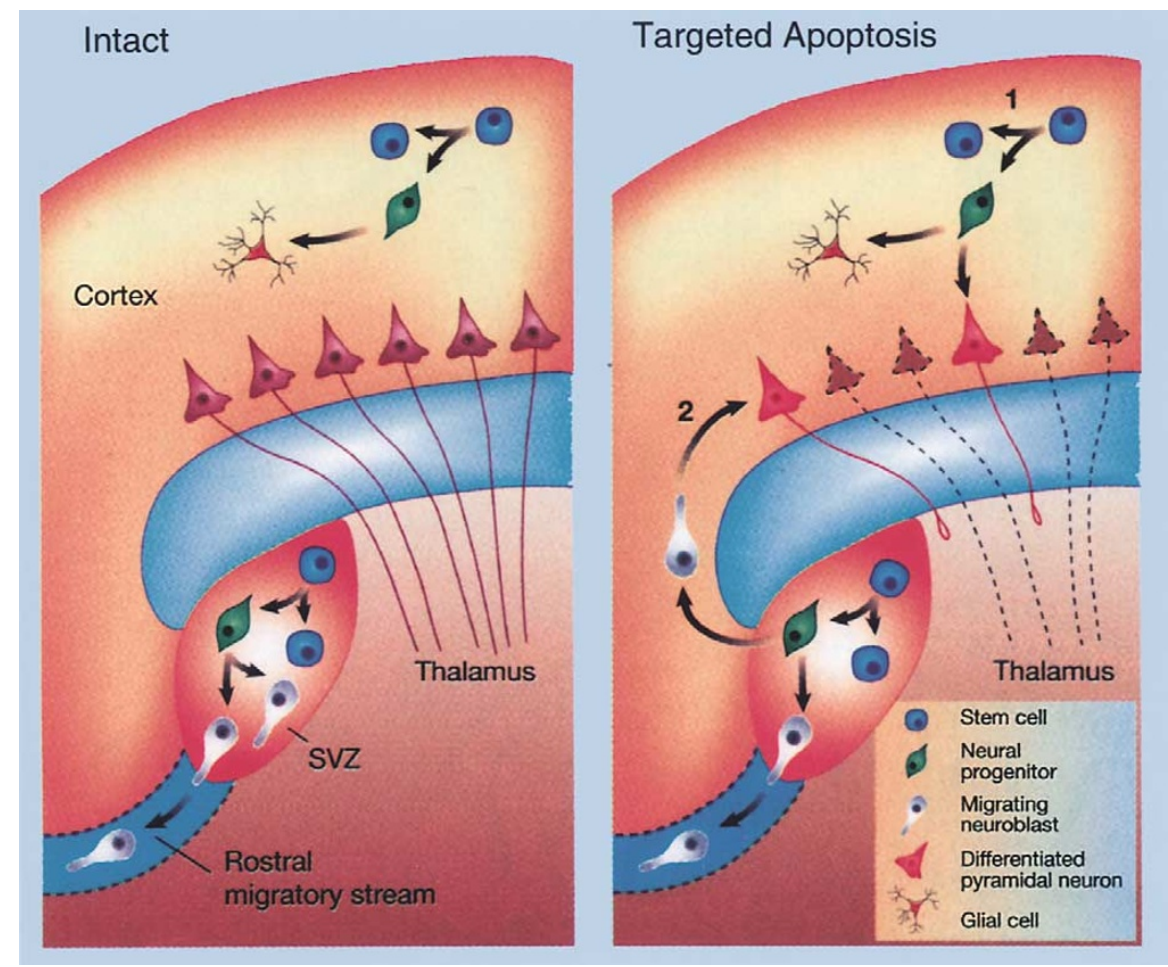

Figure 1. Induction of neurogenesis in the neocortex of adult mice. Cartoon showing targeted apoptosis of corticothalamic projection neurons and subsequent recruitment of new neurons from endogenous neural precursors, without transplantation, in adult mouse neocortex. Left: In intact adult mouse neocortex, endogenous precursors exist in the cortex itself, and in the underlying subventricular zone (SVZ). Normally, these precursors produce only glia in cortex. Neurons produced in the anterior SVZ migrate along the rostral migratory stream to the olfactory bulb (not shown). Right: When corticothalamic projection neurons are induced to undergo synchronous targeted apoptosis, new migratory neuroblasts are born from endogenous precursors. These migrate into cortex, differentiate progressively into fully mature neurons, and a subset send longdistance projections to the thalamus, the appropriate original target of the neurons being replaced. The new neurons appeared to be recruited from SVZ precursors and potentially also from precursors resident in cortex itself. Adapted from Bjorklund and Lindval (2000), Nature (news and views), 405:892-894. Reprinted by permission from Nature (C) 2000 Macmillan Magazines Ltd.

totic degeneration, immature neurons derived from E14 mice, which normally contribute to layer 5 and 6 of cortex, and E17 mice were transplanted into cortex undergoing the targeted apoptosis of layer $2 / 3$ callosal projection neurons. The transplanted immature neurons differentiated into neurons in layer $2 / 3$ and formed contralateral callosal projections, which are typical of layer $2 / 3$ neurons but absent in layer 6 neurons. We also tested the potential of two multipotent precursor cell lines: cerebellar-derived C17.2 precursor cells and hippocampus-derived HiB5 precursor cells, derived from an even early stage. Both of these multipotent precursor cell lines can differentiate into neurons and glia when transplanted into the embryonic developing brain, and differentiate only into glia (or remain undifferentiated) when transplanted into adult intact or kainic acid lesioned cortex. C17.2 cells differentiated into neurons at low efficiencies when transplanted into regions of cortex undergoing targeted apoptosis. In contrast, similarly transplanted HiB5 cellsdid not differentiate into neurons, perhaps due to the absence of functional $\operatorname{TrKB}$ receptors. These results highlight the fact that, although cortex undergoing apoptotic degeneration is instructive for neuronal differentiation and integration, the newly introduced cells must be competent to respond to such environmental signals.

Immature neurons or precursors transplanted near targeted regions of cortex migrated up to $800 \mu \mathrm{m}$ to occupy degenerating regions of cortex, while neurons or precursors transplanted into control mice remain within approximately $40 \mu \mathrm{m}$ of their injection site. Approximately $45 \%$ of transplanted E17 neurons underwent directed migration and pyramidal neuron differentiation; the rest remained in the injection site, surviving as small, presumptive, interneurons. In living slice cultures, transplanted immature neurons adopted classic migratory morphologies, with leading and trailing processes, elongated cell bodies, and underwent 
saltatory migration. They migrated across intact layer 5 and 6, toward targeted regions of cortex. The immature neurons migrated along axons and host-derived, RC-2 positive radial glial-like cells. Host astrocytes, identified by the expression of a host-specific transgene, dedifferentiated and formed transitional radial glia-like cells only in targeted cortex that contained donor cells. Most neurons completed their migration by two weeks after transplantation and had already begun extending axons toward the corpus callosum.

After migrating, transplanted immature neurons integrated into the microcircuitry of the targeted cortex. Synaptophysin staining and electron microscopy demonstrated that more than $65 \%$ of donor neurons accepted afferent input. In addition, transplanted neurons expressed neurotransmitters and neurotransmitter receptors appropriate to the region of cortex into which they were transplanted. Donor neurons expressed the same complement of neurotransmitters (glutamate, aspartate, and GABA) and receptors (kainate-R, AMPA$R$, NMDA-R. and GABA-R) as endogenous cortical projection neurons (Shin et al. 2000). Taken together, these results demonstrate that targeted cortex induces immature neurons to differentiate into neurons that closely resemble the neurons that were induced to degenerate.

Donor neurons or neural precursors transplanted into cortex undergoing apoptotic degeneration re-form specific axonal projections to the original targets of the degenerating projection neurons. Cells transplanted into control intact or kainic acid lesioned cortex do not form any long distance projections. To examine the specificity of the donor neuron's long distance projections, we transplanted immature neurons into cortex undergoing degeneration of transcallosal, cortico-cortical layer $2 / 3$ projection neurons. Using a retrograde label, we found that donor cells re-formed specific callosal connections 6 to $10 \mathrm{~mm}$ long to contralateral cortex, the original targets of the degenerating projection neurons. The donor cells did not re-form connections to closer, alternate targets of other nearby populations of S1 neurons, including ipsilateral thalamus, motor cortex, and secondary somatosensory cortex. The efficiency of this anatomic reconnectivity appears to be highly dependent on the developmental stage of the donor neuroblasts or precursors; $>40 \%$ of donor E19 neuroblasts, $21 \%$ of donor E17 neuroblasts, $10-15 \%$ of donor E14 neuroblasts, and only 1-3\% of transplanted multipotent precursors make long distance projections. The properties of the donor cells are important in determining whether they can respond to the instructive signals produced by targeted apoptosis I neocortex.

To begin to identify the molecular signals that are responsible for the instructive environment produced by cortex undergoing targeted apoptosis of projection neurons, we analyzed the gene expression of candidate neurotrophins, growth factors, and receptors in regions of targeted neuronal death. We compared gene expression to that of intact adult cortex using Northern blot analysis, in situ hybridization, and immunocytochemical analysis. The genes for BDNF, NT-4/5, and NT-3 are upregulated only in degenerating regions of cortex, specifically during the period of projection neuron apoptosis (Wang et al. 1998). The expression of a variety of other growth factors that are not as developmentally regulated is not altered. These results are in contrast to the less specific, more immediate, and short-lived changes in gene expression observed in response to non-specific necrotic injuries or seizure-induced injury. Surrounding glia and neurons may change their gene expression in response to activity dependent changes at their synapses or factors released by degenerating projection neurons. For example, BDNF is upregulated specifically by local interneurons adjacent to degenerating projection neurons. We are currently using PCRbased suppression subtraction hybridization and DNA microarray approaches to examine the expression of other known and novel factors that contribute to the instructive environment formed by cortex undergoing targeted apoptosis of projection neurons.

\section{INDUCTION OF NEUROGENESIS IN THE NEOCORTEX OF ADULT MICE}

Based on the results outlined above, we investigated the fate of endogenous multipotent precursors in cortex undergoing targeted apoptotic degeneration. Although endogenous multipotent precursors exist in the adult brain, including cortex, neurogenesis does not normally occur in postnatal mouse cortex. We examined the fates of newborn cells in targeted neocortex, an environment that is instructive for neurogenesis by exogenous precursors. In these experiments, we addressed the question of whether the normal absence of constitutive cortical neurogenesis reflects an intrinsic limitation of the endogenous neural precursors' potential, or a lack of appropriate microenvironmental signals necessary for neuronal differentiation or survival. In addition, these experiments provide information regarding whether endogenous neural precursors could potentially be manipulated in situ, toward future neuronal replacement therapies.

We found that endogenous multipotent precursors, normally located in the adult brain, could be induced to differentiate into neurons in the adult mammalian neocortex (Figure 1). We induced synchronous apoptotic degeneration (Macklis 1993; Sheen and Macklis 1995) of corticothalamic neurons in layer 6 of anterior cortex and examined the fates of dividing cells within cortex, using BrdU and markers of progressive neuronal differentiation. BrdU+ newborn cells expressed NeuN, a mature neuronal marker, and survived at least 28 weeks. 
First, subsets of BrdU+ precursors expressed Doublecortin, a protein expressed exclusively in immature, typically migrating neurons (Gleeson et al. 1999; Francis et al. 1999), and $\mathrm{Hu}$, an early neuronal marker (Marusich et al. 1994; Barami et al. 1995). We observed no new neurons in control, intact cortex. Retrograde labeling from thalamus demonstrated that newborn BrdU+ neurons can form long-distance corticothalamic connections. Together, these results demonstrate that endogenous neural precursors can be induced in situ to differentiate into cortical neurons, survive for many months, and form appropriate long-distance connections in the adult mammalian brain.

We induced synchronous apoptosis of layer 6 corticothalamic projection neurons via chromophore-targeted neuronal degeneration (Figure 2). We targeted layer 6 corticothalamic projection neurons in the anterior neocortex because they are located close to the subventricular zone, a region that contains a relatively large number of multipotent neural precursors. Chlorin $e_{6}$ conjugated nanospheres were injected into the thalamus in adult female mice, from which they were retrogradely transported to the somata of layer 6 corticothalamic projection neurons. Layer 6 anterior cortex was noninvasively exposed to long wavelength light via intact dura, inducing apoptosis of the corticothalamic projection neurons in anterior cortex. We treated mice with BrdU for the following two weeks. After 2, 5, 9, and 28 weeks of survival, we examined the phenotype of BrdU-positive (BrdU+) newborn cells using markers of developing and mature neurons and glia, including Doublecortin, $\mathrm{Hu}, \mathrm{NeuN}$, glial fibrillary acidic protein (GFAP), and myelin basic protein (MBP). We examined their axonal projections using the retrograde label FluoroGold.

We found that newborn cells differentiated into mature, NeuN-expressing, neurons and survived for at least 28 weeks. Recently born, BrdU+/NeuN+ neurons were found only in regions of cortex undergoing apoptotic degeneration of layer 6 corticothalamic projection neurons 2-28 weeks after inducing degeneration (Figure 3). To confirm that newborn cells were double-labeled and not merely closely apposed to pre-existing neurons, we imaged them using laser scanning confocal microscopy and produced 3-dimensional digital reconstructions. The reconstructions confirmed that these newborn cells were neurons. Some newborn neurons had pyramidal neuron morphology (large, 10-15 $\mu$ m diameter somata with apical processes; Figure 3, Panels a-d) characteristic of neurons that give rise to long-distance projections. In order to examine the theoretical possibility that these newborn cells were inappropriately expressing multiple phenotypic markers, we triple-labeled sections with antibodies to GFAP, an astroglial marker, and MBP, an oligodendroglial marker. BrdU $+/ \mathrm{NeuN}+$ neurons were negative for GFAP (Figure 3, Panel j) and MBP, confirming that
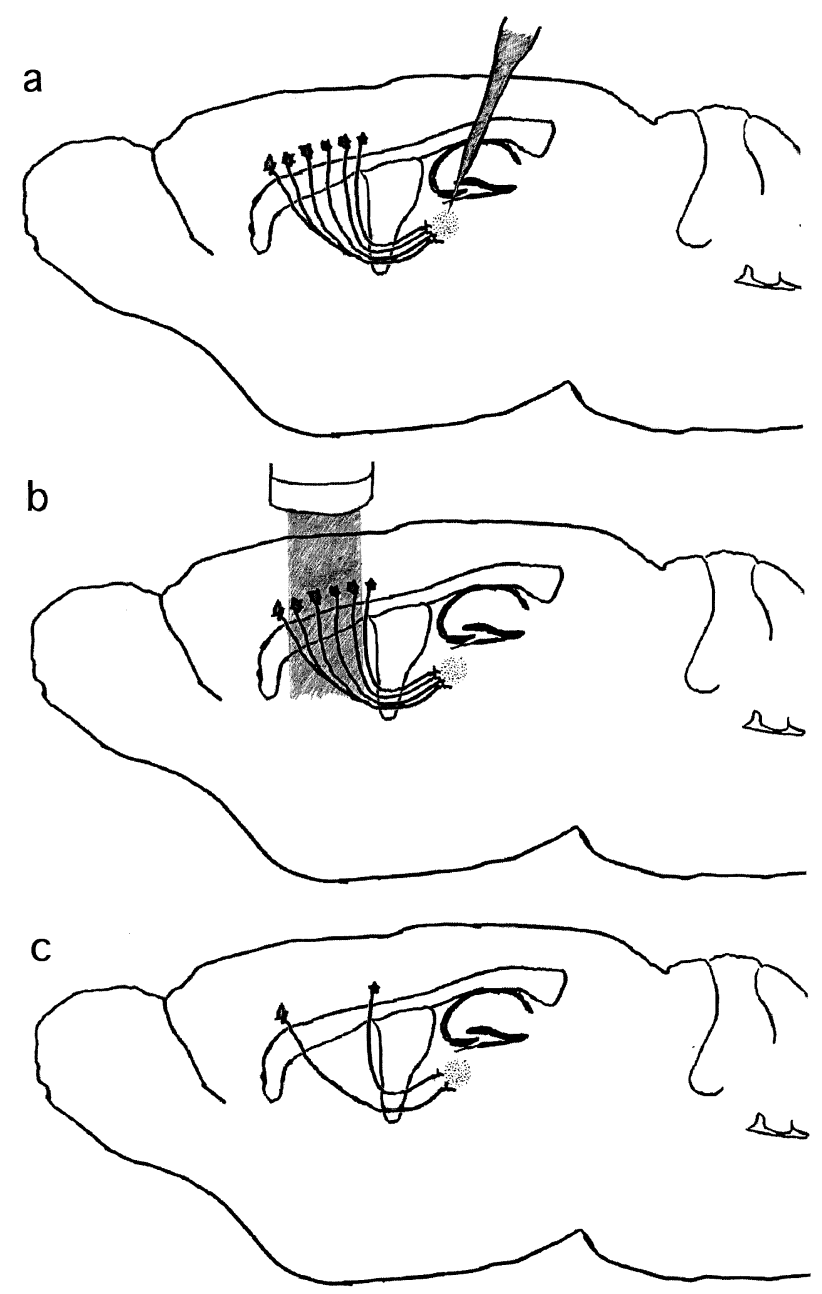

Figure 2. Biophysically targeted apoptotic neurodegeneration produces highly specific cell death of selected projection neurons within defined regions of neocortex. Degeneration results from the photoactivation of retrogradely transported nanospheres carrying the chromophore chlorin $e_{6}$, (Macklis 1993; Sheen and Macklis 1994, 1995). a: Nanospheres carrying Chlorin $e_{6}$ are injected into the axonal terminal fields of the targeted projection neurons. The nanospheres are retrogradely transported to the somata of the projection neurons and stored non-toxically within neuronal lysosomes. b: The projection neurons are then exposed to long wavelength light, which specifically induces the chlorin $e_{6}$ to produce singlet oxygen, and induces apoptosis of neurons containing chlorin $e_{6}$. c: Since neither the chlorin $e_{6}$ nor the long-wavelength light cause apoptosis by themselves, only neurons both selectively labeled with the chromophore and located in the controlled light path undergo apoptotic degeneration.

they had specifically differentiated into mature neurons. We found approximately $50-100$ newborn neurons $/ \mathrm{mm}^{3}$ following induction of apoptosis (see Table 1), while we found no newborn neurons in the neocortex of control mice at any time $(n=13)$, confirming previous reports that neurogenesis does not occur in the adult rodent 

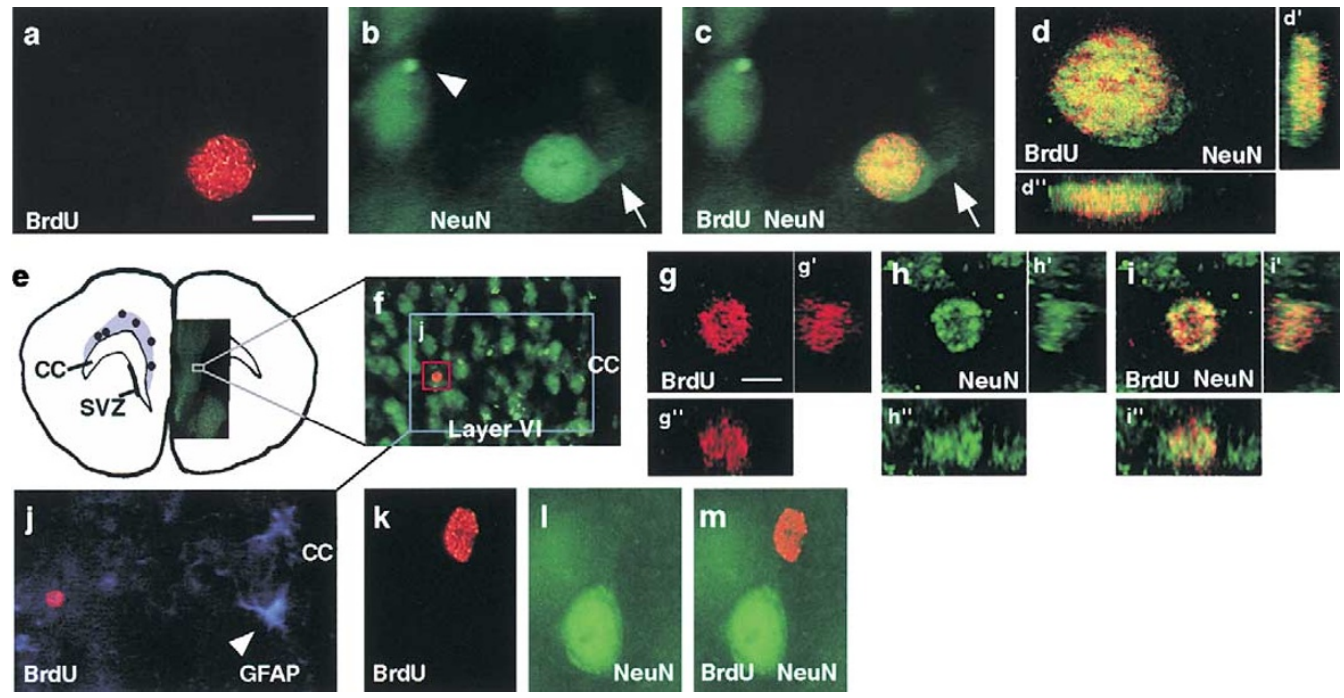

Figure 3. Newborn BrdU+ cells can be induced to differentiate into neurons, expressing NeuN, a mature neuronal marker, in regions of cortex undergoing targeted apoptotic degeneration of corticothalamic neurons. a: A large, densely stained BrdU+ nucleus (red) 28 weeks after induction of apoptosis. Scale bar: $10 \mu \mathrm{m}$. b: The BrdU+ neuron, lower right, shows typical NeuN staining, with strong nuclear and weaker cytoplasmic labeling. Apical dendrite (arrow). The neuron at left in a different focal plane remains from the original nanosphere targeting for apoptosis; a lysosome containing nanospheres is indicated (arrowhead). No BrdU+/NeuN + newborn neurons contained nanospheres, demonstrating that they are not original, targeted neurons. c: Overlay. d: Confocal images combined to produce a 3-dimensional reconstruction of this newborn neuron. $\mathrm{d}^{\prime}, \mathrm{d}^{\prime \prime}$ : cell viewed along the $\mathrm{x}$ axis and y axis, respectively, demonstrating colocalization of BrdU and NeuN. e: Left, camera lucida showing location of BrdU+/NeuN+ cells (dots) within the targeted region (gray). Right, a sample newborn neuron in cortical layer VI. Corpus callosum (CC). Subventricular zone (SVZ). f: Higher magnification view of layer VI shows a BrdU+ newborn neuron (red box). g-i: Confocal 3-d reconstruction of red boxed region. g', $h^{\prime}, i^{\prime}: X_{-}$-axis. $g^{\prime \prime}, h^{\prime \prime}, i^{\prime \prime}$ : Y-axis. g: BrdU (red), indicating the cell underwent mitosis during the two weeks following induction of apoptosis. Scale bar: $5 \mu \mathrm{m}$. h: NeuN (green). i: Merged image. BrdU (red) and NeuN (green) labeling are coincident in all three dimensions. j: The BrdU+/NeuN+ neuron (red) is GFAP-negative (blue). A GFAP+ astrocyte (arrowhead). k, l, m: The presence of $\mathrm{BrdU}+/ \mathrm{NeuN}-$ and BrdU-/NeuN+ cells demonstrate that the double labeling protocol is specific. Image from same section as a-d. k: BrdU(red) and l: NeuN(green) do not show cross-reactivity. m: Overlay. (Adapted from Magavi et al. 2000). Reprinted by permission from Nature (C) 2000 Macmillan Magazines Ltd.
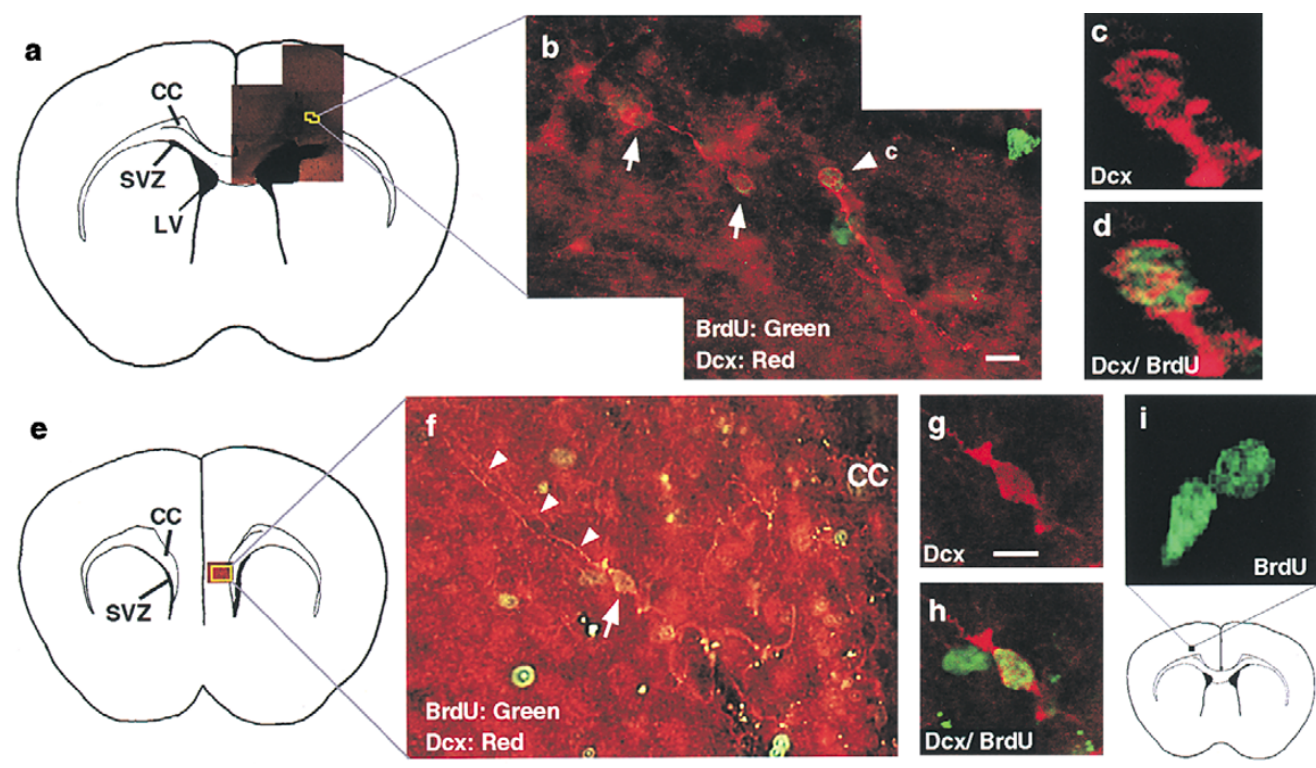
Table 1. Survival Results

\begin{tabular}{rcc}
\hline Survival & Number of BrdU+/NeuN + cells $/ \mathbf{~ m m}^{\mathbf{3}}$ & \# mice \\
\hline 2 weeks & $97 \pm 69$ & 6 \\
5 weeks & $43 \pm 20$ & 3 \\
28 weeks & $78 \pm 15$ & 2 \\
\hline
\end{tabular}

The difference between control ( 0 new neurons $/ \mathrm{mm}^{3}$ ) and experimental mice is highly statistically significant $(p<.0001,2$-tailed $t$-test). These results demonstrate that endogenous neural precursors can be induced in situ to differentiate into mature neurons and survive for at least many months in the adult murine neocortex.

brain. These results demonstrate that endogenous neural precursors can be induced in situ to differentiate into mature neurons and survive for many months in the adult murine neocortex.

To further understand the source of these newborn neurons, we examined where newly born cells were located in experimental and control animals. After two weeks of BrdU treatment, newly born, BrdU+ non-neuronal cells were found throughout both experimental and control cortex. At two weeks, experimental mice $(n=$ 6) had $5,400 \pm 1,500 \mathrm{BrdU}+$ cells per $\mathrm{mm}^{3}$ in the experimental regions, not significantly more than control mice $(n=3)$, which had 4,100 $\pm 1,700$ newborn cells per $\mathrm{mm}^{3}$. Similarly, aspiration lesions of cortex have been reported to yield inconsistent increases in BrdU labeled cells in the subventricular zone (Szele and Chesselet 1996). Previous studies have established that proliferation normally occurs in the adult cortex; however, under normal circumstances, mitotic cells differentiate into glia, remain undifferentiated, or die.

Some newborn cells located within the cortex of experimental animals appear to originate from precursors located within cortex itself, whereas a second population, which was not present in control animals, appeared to originate in or near the subventricular zone. At two weeks, pairs of BrdU + cells, apparently daughters of the same precursor, were found throughout both control and experimental cortex (Figure 3, Panel i). It is possible that some of these newborn cells are the daughters of cortically located adult multipotent neural precursors that have been described in vitro (Palmer et al. 1999; Marmur et al. 1998). The adult subventricular and ependymal zones, located subjacent to the deep layers of cortex containing degenerating projection neurons, also contain a population of constitutively dividing, multipotent neural precursors (Altman 1969; Reynolds and Weiss 1992; Richards et al. 1992; Luskin 1993; Vescovi et al. 1993; Lois and Alvarez-Buylla 1993; Morshead et al. 1994), and appear to be the source of the second population of newborn cells. Cells from the SVZ population, and perhaps both of these populations, may contribute to induced cortical neurogenesis.

We investigated the early differentiation and migration of the newborn neurons using a marker of early postmitotic neurons, Doublecortin (Dcx). In experimental mice only, newborn BrdU+/Dcx+ neurons with migratory morphologies appeared to migrate from the SVZ through the corpus callosum (Figure 4, Panels a-d) and into experimental regions of cortex (Figure 4, Panels e,f). Doublecortin is a microtubule-associated protein that is exclusively expressed in immature migrating and differentiating neurons, but is not detectable in mature neurons (Gleeson et al. 1999; Francis et al. 1999). Confocal analysis confirmed that these BrdU+ cells express Doublecortin (Figure 4, Panels c,d). No BrdU+ / Dcx + cells were found in the corpus callosum or cortex of control animals. However, they exist in the rostral migratory stream of both controls and experimentals, as previously described (Gleeson et al. 1999; Francis et al. 1999). Newly born BrdU+/Dcx+ neurons within the corpus callosum displayed morphologies characteristic of migrating neurons, while newborn Dcx + neurons located in deep layers of cortex displayed more complex morphologies with apical processes that suggest their further differentiation. These results demonstrate the progressive differentiation of endogenous precursors: first into Dcx + migratory neuroblasts, then into immature Dcx+ neurons with process extension, then into more mature neurons.

The location of Dcx + neurons suggests that at least some of the newborn neurons that form in targeted cortex are derived directly from SVZ precursors. However, these data do not rule out the possibility that other precursors contribute to neurogenesis. Newly born cortical neurons could theoretically be derived in three different ways. Newly born neurons could arise from endog-

Figure 4. Newborn cells express the immature, typically migratory neuronal marker Doublecortin (Dcx) two weeks after induction of apoptosis. BrdU+/Dcx+ neurons appear to migrate from the SVZ, through the corpus callosum, and into experimental regions of cortex. a: Camera lucida showing BrdU+ (green) / Dcx+ (red) neurons within the superficial corpus callosum (CC). Lateral ventricle (LV). b: Fluorescence micrograph of three BrdU+ /Dcx+ neurons. Scale bar: $25 \mu \mathrm{m}$. $\mathbf{c}$, d: Confocal micrographs confirm that the neuron in $\mathrm{b}$ (arrowhead) is BrdU+/Dcx+. e: Camera lucida: $\mathrm{A} B r d U+/ \mathrm{Dcx}+$ newborn neuron within cortex. f: Higher magnification: the differentiating BrdU+/ Dcx + newborn neuron (arrow) extending processes (arrowheads) in cortex. No BrdU+/Dcx + cells were found in the CC or cortex of control mice. Dcx staining is specific for migrating neurons(Gleeson et al. 1999; Francis et al. 1999); it does not overlap with A2B5, O4, RIP, MBP, or GFAP staining (see methods). $\mathbf{g}$, h: Confocal micrographs of this newborn neuron confirm that it is BrdU+/Dcx + . Scale bar: 10 $\mu \mathrm{m}$. i: Pairs of BrdU+ non-neuronal cells were found throughout cortex in experimental and control mice. (Adapted from Magavi et al. 2000). Reprinted by permission from Nature (c) 2000 Macmillan Magazines Ltd. 
enous cortical precursors, directly from SVZ precursors, or from endogenous precursors, such as SVZ precursors, that enter cortex and then divide within cortex. Neuronal replacement therapies that depend on precursors derived from normally neurogenic portions of the brain could be limited to regions of the brain that are adjacent to these neurogenic regions. Thus, further understanding the source of the cells that can contribute to induced neurogenesis could be critical for deciding whether endogenous precursors could potentially form the basis of effective neuronal replacement therapies.

The continued differentiation of these newborn neurons was examined using antibodies to $\mathrm{Hu}$, an RNAbinding protein that begins to be expressed in neuronal nuclei and somata soon after differentiation (Marusich et al. 1994; Barami et al. 1995). BrdU $+/ \mathrm{Hu}+$ neurons with large, ovoid nuclei were found in the cortex of experimental mice two weeks after induction of apoptosis (Figure 5), whereas no $\mathrm{BrdU}+/ \mathrm{Hu}+$ cells were found in control mice. We used Hoechst 33258, which stains DNA, as a nuclear counterstain that allowed us to confirm that a specific nucleus belonged to a particular cell. The dispersed heterochromatin pattern demonstrated by Hoechst staining coincident with the BrdU+ nuclei is characteristic of neuronal nuclei and further confirms $\mathrm{BrdU}+/ \mathrm{Hu}+$ double labeling. The expression of $\mathrm{Hu}$ further confirms induced cortical neuron differentiation by endogenous neural precursors.

These newborn neurons derived from endogenous precursors can re-form long distance projections. To examine the identities of the newborn BrdU+ neurons
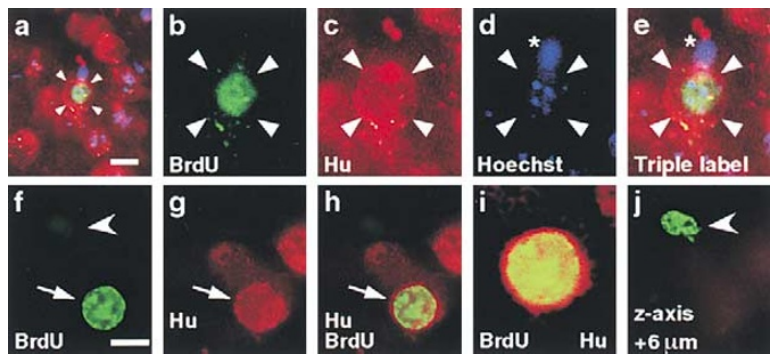

Figure 5. Newborn BrdU + cells express the early neuronal marker, $\mathrm{Hu}$ in experimental cortex. a: $\mathrm{A} \mathrm{BrdU}+/ \mathrm{Hu}+$ newborn neuron (arrowheads) at two weeks. Surrounding neurons are BrdU-negative. Scale bar: $10 \mu \mathrm{m}$. b-e: Higher magnification. b: BrdU (green) labels the nucleus of a newborn neuron. c: $\mathrm{Hu}$ (red) labels the BrdU+ newborn cell. d: Hoechst (blue) shows the large, dispersed nucleus of the newborn neuron and the compact nucleus of an adjacent glial cell (asterisk). e: Overlay. f: Arrow indicates BrdU+ (green) nucleus of a $\mathrm{BrdU}+/ \mathrm{Hu}+$ neuron at 28 weeks. Arrowhead indicates a BrdU $+/ \mathrm{Hu}$ - cell in another plane of focus. g: Hu+ soma (red) h: Overlay. i: Confocal confirmation of double labeling. $\mathrm{j}: \mathrm{A} \mathrm{BrdU}+/ \mathrm{Hu}-$ cell located in a focal plane $6 \mu \mathrm{m}$ higher demonstrates specificity of staining. (Adapted from Magavi et al. 2000). Reprinted by permission from Nature (c) 2000 Macmillan Magazines Ltd. and examine their potential ability to establish long distance connections, we injected the retrograde label FluoroGold into the same thalamic sites as the original nanosphere injections. Previous experiments from our lab show that large numbers of embryonic neurons transplanted into regions of adult cortex undergoing apoptotic degeneration of projection neurons can reform long distance connections to the original targets of the degenerating neurons (Hernit-Grant and Macklis 1996). At 9 weeks, we observed newborn BrdU+ neurons retrogradely labeled with FluoroGold that had large nuclei and large cell bodies denoting pyramidal projection neuron morphology (Figure 6). These results show that endogenous precursors that differentiate into mature neurons can establish appropriate, long-distance corticothalamic connections in the adult brain.

Several lines of evidence reinforce that $\mathrm{BrdU}+$ neurons in these experiments are newborn neurons, and not pre-existing neurons artifactually labeled by BrdU due to DNA synthesis during apoptosis, as has been seen in some cell culture experiments. First, we directly controlled for this theoretical possibility, since the photoac-

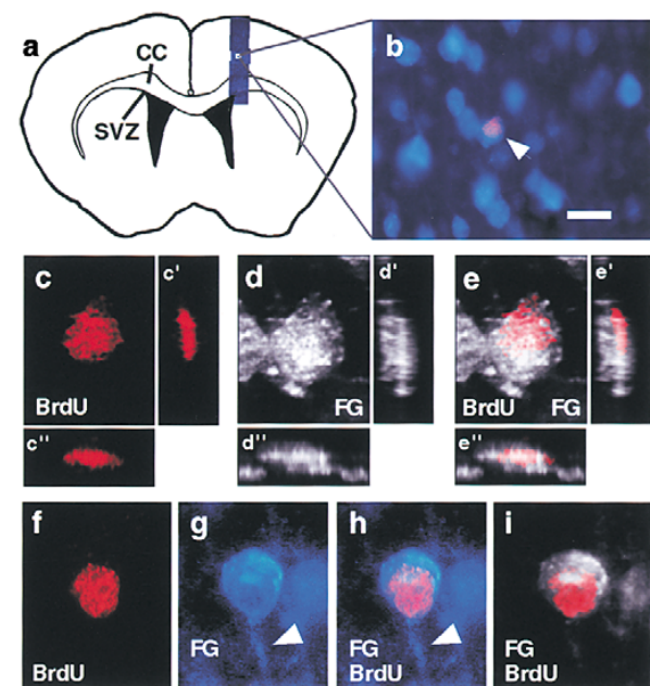

Figure 6. Newborn BrdU+ neurons in experimental cortex extend long-distance projections to thalamus. a: Camera lucida of a BrdU+ (red) / FG + (white) retrogradely labeled neuron in layer VI of cortex at 9 weeks. Corpus callosum (CC) b: Higher magnification shows the newborn corticothalamic neuron (arrow) and FG+/BrdU- original neurons. Scale bar: $20 \mu \mathrm{m}$. c-e: Confocal 3-dimensional reconstruction of the neuron. $\mathrm{c}^{\prime}, \mathrm{d}^{\prime}, \mathrm{e}^{\prime}$ : X-axis. $\mathrm{c}^{\prime \prime}, \mathrm{d}^{\prime \prime}{ }^{\prime}, \mathrm{e}^{\prime \prime}$ : Y-axis. c: BrdU+ nucleus, indicating the cell underwent mitosis in the two weeks following induction of apoptosis. d: FluoroGold+ soma, indicating that this neuron projects to thalamus. e: Merged image, confirming double-labeling in three dimensions. f: BrdU+ (red) nucleus of an adult-born FG+ corticothalamic neuron. g: FG+ (blue) cell body with labeled axon (arrow). h: Overlay. i: Confocal microscopy confirms double labeling. (Adapted from Magavi et al. 2000). Reprinted by permission from Nature (C) 2000 Macmillan Magazines Ltd. 
tive targeting nanospheres we employed also carry a fluorescent label, allowing us to identify all neurons targeted to undergo apoptosis. No BrdU + cell was a targeted neuron, and no targeted neuron was BrdU+. Second, the appearance of BrdU incorporation during DNA repair is that of minor nuclear speckling, and not uniform, whole-nucleus labeling as we observed in these experiments. Third, BrdU+ neurons were present in neocortex over six months after the end of the BrdU treatment, demonstrating their viability and long-term survival. Fourth, and perhaps arguing most definitively for the identification of BrdU+ neurons as newborn neurons is the fact that we were able to trace the early developmental progression of these neurons using Doublecortin, an immature migratory neuronal marker. We found BrdU + / Doublecortin + newborn neurons with migratory morphologies in the corpus callosum and appropriate cortical layer 6 of experimental mice, and we identified BrdU + / Doublecortin + immature neurons extending early processes in these regions. Further, we have also conducted experiments investigating whether BrdU integrates into dying cells in vivo, or whether this is simply a theoretical concern from in vitro studies. We examined apoptotic neurons in early postnatal brain ( $\mathrm{n}>$ 1000) and neurons undergoing excitotoxic degeneration induced by ibotinic acid in adult animals $(n>5000)$. Absolutely no apoptotic, cleaved caspase-3 positive, or dying neurons with pyknotic, condensed nuclei integrated BrdU, even when BrdU doses three to eight times higher than normal were used. From this combination of evidence, we conclude that healthy, long-lived neurons with dense BrdU labeling throughout their nuclei can be reliably identified as newborn neurons.

Taken together, our results demonstrate that endogenous neural precursors can be induced to differentiate into neocortical neurons in a layer and region-specific manner and re-form appropriate corticothalamic connections in regions of adult mammalian neocortex that do not normally undergo neurogenesis. The same microenvironment that supports the migration, neuronal differentiation, and appropriate axonal extension of transplanted neuroblasts and precursors also supports and instructs the neuronal differentiation and axon extension of endogenous precursors.

\section{CONCLUSIONS}

Recent research suggests that it may be possible to manipulate endogenous neural precursors in situ to undergo neurogenesis in the adult brain, toward future neuronal replacement therapy for neurodegenerative disease and other CNS injury. Multipotent precursors, capable of differentiating into astroglia, oligodendroglia, and neurons exist in many portions of the adult brain. These precursors have considerable plasticity, and, although they may have limitations in their integration into some host sites (Young et al. 2000), they are capable of differentiation into neurons appropriate to a wide variety of recipient regions, when heterotopically transplanted (Suhonen et al. 1996). Many adult precursors are capable of migrating long distances, using both tangential and radial forms of migration (Lois and Alvarez-Buylla 1994; Doetsch and Alvarez-Buylla 1996; Luskin and Boone 1994). Endogenous adult neural precursors are also capable of extending axons significant distances through the adult brain (Magavi et al. 2000; Barber 1982; Crews and Hunter 1994). In addition, in vitro and in vivo experiments have begun to elucidate the responses of endogenous precursors to both growth factors and behavioral manipulations, and are beginning to provide key information toward manipulation of their proliferation and differentiation. Recent experiments from our lab have shown that, under appropriate conditions, endogenous precursors can differentiate into neurons, extend long distance axonal projections, and survive for long periods of time in regions of the adult brain that do not normally undergo neurogenesis. These results indicate that there exists a sequence and combination of molecular signals by which neurogenesis can be induced in the adult mammalian cerebral cortex, where it does not normally occur.

Together, these data suggest that neuronal replacement therapies based on manipulation of endogenous precursors may be possible in the future. However, several questions must be answered before neuronal replacement therapies using endogenous precursor become a reality. The multiple signals that are responsible for endogenous precursor division, migration, differentiation, and axon extension will need to be elucidated in order for such therapies to be developed efficiently. These challenges also exist for neuronal replacement therapies based on transplantation of precursors, since donor cells, whatever their source, must interact with the mature CNS's environment in order to integrate into the brain. In addition, it remains an open question whether potential therapies manipulating endogenous precursors in situ would be necessarily limited to portions of the brain near adult neurogenic regions. However, even if multipotent precursors are not located in very high numbers outside of neurogenic regions of the brain, it may be possible to induce them to proliferate from the smaller numbers that are more widely distributed throughout the neuraxis. Research in this field is promising, and we may one day be able to induce the brain to heal itself. But this field is still young and we do not even yet know all the questions we will need to ask.

\section{ACKNOWLEDGMENTS}

This work was partially supported by grants from the NIH (NS41590, HD28478, MRRC HD18655), the Alzheimer's Associ- 
ation, the Human Frontiers Science Program, and the National Science foundation to J.D.M. S.S.M. was partially supported by an NIH predoctoral training grant and fellowships from the Leopold Schepp Foundation and the Lefler Foundation.

\section{REFERENCES}

Aberg MA, Aberg ND, Hedbacker H, Oscarsson J, Eriksson PS (2000): Peripheral infusion of IGF-I selectively induces neurogenesis in the adult rat hippocampus. J Neurosci 20:2896-2903

Ahmed S, Reynolds BA, Weiss S (1995): BDNF enhances the differentiation but not the survival of CNS stem cellderived neuronal precursors. J Neurosci 15:5765-5778

Altman J (1969): Autoradiographic and histological studies of postnatal neurogenesis. IV. Cell proliferation and migration in the anterior forebrain, with special reference to persisting neurogenesis in the olfactory bulb. J Comp Neurol 137:433-457

Altman J, Das GD (1965): Autoradiographic and histological evidence of postnatal hippocampal neurogenesis in rats. J Comp Neurol 124:319-335

Alvarez-Buylla A, Kirn JR, Nottebohm F (1990): Birth of projection neurons in adult avian brain may be related to perceptual or motor learning [published erratum appears in Science (October 19, 1990) 250:360]. Science 249:1444-1446

Arsenijevic Y, Weiss S (1998): Insulin-like growth factor-I is a differentiation factor for postmitotic CNS stem cellderived neuronal precursors: distinct actions from those of brain-derived neurotrophic factor. J Neurosci 18:2118-2128

Barami K, Iversen K, Furneaux H, Goldman SA (1995): Hu protein as an early marker of neuronal phenotypic differentiation by subependymal zone cells of the adult songbird forebrain. J Neurobiol 28:82-101

Barber PC (1982): Neurogenesis and regeneration in the primary olfactory pathway of mammals. Bibliotheca Anatomica 23:12-25

Bengzon J, Kokaia Z, Elmer E, Nanobashvili A, Kokaia M, Lindvall O (1997): Apoptosis and proliferation of dentate gyrus neurons after single and intermittent limbic seizures. Proc Natl Acad Sci USA 94:10432-10437

Bernier PJ, Vinet J, Cossette M, Parent A (2000): Characterization of the subventricular zone of the adult human brain: evidence for the involvement of Bcl-2. Neurosci Res 37:67-78

Bjorklund A, Lindvall O (2000): Cell replacement therapies for central nervous system disorders. Nat Neurosci 3: $537-544$

Brewer GJ (1999): Regeneration and proliferation of embryonic and adult rat hippocampal neurons in culture. [see comments]. Exp Neurol 159:237-247

Brezun JM, Daszuta A (1999): Depletion in serotonin decreases neurogenesis in the dentate gyrus and the subventricular zone of adult rats. Neuroscience 89:999-1002

Brockes JP (1997): Amphibian limb regeneration: rebuilding a complex structure. Science 276:81-87

Caggiano M, Kauer JS, Hunter DD (1994): Globose basal cells are neuronal progenitors in the olfactory epithe- lium: a lineage analysis using a replication-incompetent retrovirus. Neuron 13:339-352

Calof AL, Hagiwara N, Holcomb JD, Mumm JS, Shou J (1996): Neurogenesis and cell death in olfactory epithelium. J Neurobiol 30:67-81

Calof AL, Rim PC, Askins KJ, Mumm JS, Gordon MK, Iannuzzelli P, Shou J (1998): Factors regulating neurogenesis and programmed cell death in mouse olfactory epithelium. Ann N Y Acad Sci 855:226-229

Cameron HA, McKay RD (1999): Restoring production of hippocampal neurons in old age. Nat Neurosci 2:894-897

Carr VM, Farbman AI (1992): Ablation of the olfactory bulb up-regulates the rate of neurogenesis and induces precocious cell death in olfactory epithelium. Exp Neurol 115:55-59

Chen G, Rajkowska G, Du F, Seraji-Bozorgzad N, Manji HK (2000): Enhancement of hippocampal neurogenesis by lithium. J Neurochem 75:1729-1734

Chiasson BJ, Tropepe V, Morshead CM, van der Kooy D (1999): Adult mammalian forebrain ependymal and subependymal cells demonstrate proliferative potential, but only subependymal cells have neural stem cell characteristics. J Neurosci 19:4462-4471

Clarke DL, Johansson CB, Wilbertz J, Veress B, Nilsson E, Karlstrom H, Lendahl U, Frisen J (2000): Generalized potential of adult neural stem cells. [see comments]. Science 288:1660-1663

Craig CG, Tropepe V, Morshead CM, Reynolds BA, Weiss S, van der Kooy D (1996): In vivo growth factor expansion of endogenous subependymal neural precursor cell populations in the adult mouse brain. J Neurosci 16: 2649-2658

Crews L, Hunter D (1994): Neurogenesis in the olfactory epithelium. Perspect Dev Neurobiol 2:151-161

Derrick BE, York AD, Martinez Jr JL (2000): Increased granule cell neurogenesis in the adult dentate gyrus following mossy fiber stimulation sufficient to induce longterm potentiation. Brain Res 857:300-307

Doetsch F, Alvarez-Buylla A (1996): Network of tangential pathways for neuronal migration in adult mammalian brain. Proc Natl Acad Sci USA 93:14895-14900

Doetsch F, Caille I, Lim DA, Garcia-Verdugo JM, AlvarezBuylla A (1999): Subventricular zone astrocytes are neural stem cells in the adult mammalian brain. Cell 97: 703-716

Duman RS, Nakagawa S, Malberg J (2001): Regulation of adult neurogenesis by antidepressant treatment. Neuropsychopharmacology 25:836-844

Eriksson PS, Perfilieva E, Bjork-Eriksson T, Alborn AM, Nordborg C, Peterson DA, Gage FH (1998): Neurogenesis in the adult human hippocampus [see comments]. Nat Med 4:1313-1317

Fischer AJ, Rey TA (2001): Muller glia are a potential source of neural regeneration in the postnatal chicken retina. Nat Neurosci 4:247-252

Francis F, Koulakoff A, Boucher D, Chafey P, Schaar B, Vinet MC, Friocourt G, McDonnell N, Reiner O, Kahn A, McConnell SK, Berwald-Netter Y, Denoulet P, Chelly J (1999): Doublecortin is a developmentally regulated, microtubule-associated protein expressed in migrating and differentiating neurons. Neuron 23:247-256 
Gage FH, Kempermann G, Palmer TD, Peterson DA, Ray J (1998): Multipotent progenitor cells in the adult dentate gyrus. J Neurobiol 36:249-266

Garcia-Verdugo JM, Doetsch F, Wichterle H, Lim DA, Alvarez-Buylla A (1998): Architecture and cell types of the adult subventricular zone: in search of the stem cells. J Neurobiol 36:234-248

Gates MA, Thomas LB, Howard EM, Laywell ED, Sajin B, Faissner A, Gotz B, Silver J, Steindler DA (1995): Cell and molecular analysis of the developing and adult mouse subventricular zone of the cerebral hemispheres. J Comp Neurol 361:249-266

Gleeson JG, Lin PT, Flanagan LA, Walsh CA (1999): Doublecortin is a microtubule-associated protein and is expressed widely by migrating neurons. Neuron 23: 257-271

Goldman SA, Kirschenbaum B, Harrison-Restelli C, Thaler HT (1997): Neuronal precursors of the adult rat subependymal zone persist into senescence, with no decline in spatial extent or response to BDNF. J Neurobiol 32:554-566

Gould E, Tanapat P (1997): Lesion-induced proliferation of neuronal progenitors in the dentate gyrus of the adult rat. Neuroscience 80:427-436

Gould E, Cameron HA, Daniels DC, Woolley CS, McEwen BS (1992): Adrenal hormones suppress cell division in the adult rat dentate gyrus. J Neurosci 12:3642-3650

Gould E, McEwen BS, Tanapat P, Galea LA, Fuchs E (1997): Neurogenesis in the dentate gyrus of the adult tree shrew is regulated by psychosocial stress and NMDA receptor activation. J Neurosci 17:2492-2498

Gould E, Beylin A, Tanapat P, Reeves A, Shors TJ (1999a): Learning enhances adult neurogenesis in the hippocampal formation [see comments]. Nat Neurosci 2:260-265

Gould E, Reeves AJ, Fallah M, Tanapat P, Gross CG, Fuchs E (1999b): Hippocampal neurogenesis in adult Old World primates. Proc Natl Acad Sci USA 96:5263-5267

Gould E, Reeves AJ, Graziano MS, Gross CG (1999c): Neurogenesis in the neocortex of adult primates. [see comments]. Science 286:548-552

Gould E, Tanapat P, McEwen BS, Flugge G, Fuchs E (1998): Proliferation of granule cell precursors in the dentate gyrus of adult monkeys is diminished by stress. Proc Natl Acad Sci USA 95:3168-3171

Graziadei GA, Graziadei PP (1979): Neurogenesis and neuron regeneration in the olfactory system of mammals. II. Degeneration and reconstitution of the olfactory sensory neurons after axotomy. J Neurocytol 8:197-213

Gritti A, Cova L, Parati EA, Galli R, Vescovi AL (1995): Basic fibroblast growth factor supports the proliferation of epidermal growth factor-generated neuronal precursor cells of the adult mouse CNS. Neuroscience Letters 185:151-154

Gritti A, Frolichsthal-Schoeller P, Galli R, Parati EA, Cova L, Pagano SF, Bjornson CR, Vescovi AL (1999): Epidermal and fibroblast growth factors behave as mitogenic regulators for a single multipotent stem cell-like population from the subventricular region of the adult mouse forebrain. J Neurosci 19:3287-3297

Gritti A, Parati EA, Cova L, Frolichsthal P, Galli R, Wanke E, Faravelli L, Morassutti DJ, Roisen F, Nickel DD, Vescovi
AL (1996): Multipotential stem cells from the adult mouse brain proliferate and self-renew in response to basic fibroblast growth factor. J Neurosci 16:1091-1100

Gross RE, Mehler MF, Mabie PC, Zang Z, Santschi L, Kessler JA (1996): Bone morphogenetic proteins promote astroglial lineage commitment by mammalian subventricular zone progenitor cells. Neuron 17:595-606

Gu W, Brannstrom T, Wester P (2000): Cortical neurogenesis in adult rats after reversible photothrombotic stroke. J Cereb Blood Flow Metab 20:1166-1173

Hastings NB, Gould E (1999): Rapid extension of axons into the CA3 region by adult-generated granule cells [published erratum appears in J Comp Neurol 415:144]. J Comp Neurol 413:146-154

Hernit-Grant CS, Macklis JD (1996): Embryonic neurons transplanted to regions of targeted photolytic cell death in adult mouse somatosensory cortex re-form specific callosal projections. Exp Neurol 139:131-142

Herrera DG, Garcia-Verdugo JM, Alvarez-Buylla A (1999): Adult-derived neural precursors transplanted into multiple regions in the adult brain. Ann Neurol 46:867-877

Hitchcock PF, Lindsey Myhr KJ, Easter SS, Mangione-Smith $\mathrm{R}$, Jones DD (1992): Local regeneration in the retina of the goldfish. J Neurobiol 23:187-203

$\mathrm{Hu}$ H, Rutishauser U (1996): A septum-derived chemorepulsive factor for migrating olfactory interneuron precursors. Neuron 16:933-940

Hu H, Tomasiewicz H, Magnuson T, Rutishauser U (1996): The role of polysialic acid in migration of olfactory bulb interneuron precursors in the subventricular zone. Neuron 16:735-743

Huang L, Cilio MR, Silveira DC, McCabe BK, Sogawa Y, Stafstrom CE, Holmes GL (1999): Long-term effects of neonatal seizures: a behavioral, electrophysiological, and histological study. Brain Res Developmental Brain Res 118: 99-107

Huard JM, Schwob JE (1995): Cell cycle of globose basal cells in rat olfactory epithelium. Dev Dyn 203:17-26

Jacobs BL, van Praag H, Gage FH (2000): Adult brain neurogenesis and psychiatry: a novel theory of depression. Molec Psych 5:262-269

Johansson CB, Svensson M, Wallstedt L, Janson AM, Frisen J (1999): Neural stem cells in the adult human brain. Exp Cell Res 253:733-736

Johns PR, Easter SS (1977): Growth of the adult goldfish eye. II. Increase in retinal cell number. J Comp Neurol 176:331-341

Jones JE, Corwin JT (1993): Replacement of lateral line sensory organs during tail regeneration in salamanders: identification of progenitor cells and analysis of leukocyte activity. J Neurosci 13:1022-1034

Kaplan MS (1981): Neurogenesis in the 3-month-old rat visual cortex. J Comp Neurol 195:323-338

Kempermann G, Kuhn HG, Gage FH (1997): More hippocampal neurons in adult mice living in an enriched environment. Nature 386:493-495

Kempermann G, van Praag H, Gage FH (2000): Activitydependent regulation of neuronal plasticity and self repair. Prog Brain Res 127:35-48

Kirschenbaum B, Goldman SA (1995): Brain-derived neurotrophic factor promotes the survival of neurons aris- 
ing from the adult rat forebrain subependymal zone. Proc Natl Acad Sci USA 92:210-214

Kirschenbaum B, Doetsch F, Lois C, Alvarez-Buylla A (1999): Adult subventricular zone neuronal precursors continue to proliferate and migrate in the absence of the olfactory bulb. J Neurosci 19:2171-2180

Kirschenbaum B, Nedergaard M, Preuss A, Barami K, Fraser RA, Goldman SA (1994): In vitro neuronal production and differentiation by precursor cells derived from the adult human forebrain. Cereb Cortex 4:576-589

Kornack DR, Rakic P (1999): Continuation of neurogenesis in the hippocampus of the adult macaque monkey. Proc Natl Acad Sci USA 96:5768-5773

Kuhn HG, Dickinson-Anson H, Gage FH (1996): Neurogenesis in the dentate gyrus of the adult rat: age-related decrease of neuronal progenitor proliferation. J Neurosci 16:2027-2033

Kuhn HG, Winkler J, Kempermann G, Thal LJ, Gage FH (1997): Epidermal growth factor and fibroblast growth factor-2 have different effects on neural progenitors in the adult rat brain. J Neurosci 17:5820-5829

Kukekov VG, Laywell ED, Suslov O, Davies K, Scheffler B, Thomas LB, O'Brien TF, Kusakabe M, Steindler DA (1999): Multipotent stem/progenitor cells with similar properties arise from two neurogenic regions of adult human brain. Exp Neurol 156:333-344

Law AK, Pencea V, Buck CR, Luskin MB (1999): Neurogenesis and neuronal migration in the neonatal rat forebrain anterior subventricular zone do not require GFAP-positive astrocytes. Dev Biol (Orlando) 216:622-634

Laywell ED, Rakic P, Kukekov VG, Holland EC, Steindler DA (2000): Identification of a multipotent astrocytic stem cell in the immature and adult mouse brain. Proc Natl Acad Sci USA 97:13883-13888

Lim DA, Fishell GJ, Alvarez-Buylla A (1997): Postnatal mouse subventricular zone neuronal precursors can migrate and differentiate within multiple levels of the developing neuraxis. Proc Natl Acad Sci USA 94:1483214836

Lois C, Alvarez-Buylla A (1993): Proliferating subventricular zone cells in the adult mammalian forebrain can differentiate into neurons and glia. Proc Natl Acad Sci USA 90:2074-2077

Lois C, Alvarez-Buylla A (1994): Long-distance neuronal migration in the adult mammalian brain. Science 264 : $1145-1148$

Lopez-Garcia C, Molowny A, Martinez-Guijarro FJ, BlascoIbanez JM, Luis de la Iglesia JA, Bernabeu A, GarciaVerdugo JM (1992): Lesion and regeneration in the medial cerebral cortex of lizards. Histol Histopathol 7:725-746

Lowenstein DH, Arsenault L (1996): The effects of growth factors on the survival and differentiation of cultured dentate gyrus neurons. J Neurosci 16:1759-1769

Luskin MB (1993): Restricted proliferation and migration of postnatally generated neurons derived from the forebrain subventricular zone. Neuron 11:173-189

Luskin MB, Boone MS (1994): Rate and pattern of migration of lineally-related olfactory bulb interneurons generated postnatally in the subventricular zone of the rat. Chemical Senses 19:695-714
Macklis JD (1993): Transplanted neocortical neurons migrate selectively into regions of neuronal degeneration produced by chromophore-targeted laser photolysis. J Neurosci 13:3848-3863

Madison R, Macklis JD (1993): Noninvasively induced degeneration of neocortical pyramidal neurons in vivo: selective targeting by laser activation of retrogradely transported photolytic chromophore. Exp Neurol 121: 153-159

Magavi SS, Leavitt BR, Macklis JD (2000): Induction of neurogenesis in the neocortex of adult mice [see comments]. Nature 405:951-955

Magloczky Z, Freund TF (1993): Selective neuronal death in the contralateral hippocampus following unilateral kainate injections into the CA3 subfield. Neuroscience 56:317-335

Malberg JE, Eisch AJ, Nestler EJ, Duman RS (2000): Chronic antidepressant treatment increases neurogenesis in adult rat hippocampus. J Neurosci (Online) 20:91049110

Markakis EA, Gage FH (1999): Adult-generated neurons in the dentate gyrus send axonal projections to field CA3 and are surrounded by synaptic vesicles. J Comp Neurol 406:449-460

Marmur R, Mabie PC, Gokhan S, Song Q, Kessler JA, Mehler MF (1998): Isolation and developmental characterization of cerebral cortical multipotent progenitors. Dev Biol (Orlando) 204:577-591

Marusich MF, Furneaux HM, Henion PD, Weston JA (1994): $\mathrm{Hu}$ neuronal proteins are expressed in proliferating neurogenic cells. J Neurobiol 25:143-155

Mason HA, Ito S, Corfas G (2001): Extracellular signals that regulate the tangential migration of olfactory bulb neuronal precursors: inducers, inhibitors and repellents. J Neurosci (submitted)

Montaron MF, Petry KG, Rodriguez JJ, Marinelli M, Aurousseau C, Rougon G, Le Moal M, Abrous DN (1999): Adrenalectomy increases neurogenesis but not PSANCAM expression in aged dentate gyrus. European J Neurosci 11:1479-1485

Morshead CM, Reynolds BA, Craig CG, McBurney MW, Staines WA, Morassutti D, Weiss S, van der Kooy D (1994): Neural stem cells in the adult mammalian forebrain: a relatively quiescent subpopulation of subependymal cells. Neuron 13:1071-1082

Newman MP, Feron F, Mackay-Sim A (2000): Growth factor regulation of neurogenesis in adult olfactory epithelium. Neuroscience 99:343-350

Nishida A, Takahashi M, Tanihara H, Nakano I, Takahashi JB, Mizoguchi A, Ide C, Honda Y (2000): Incorporation and differentiation of hippocampus-derived neural stem cells transplanted in injured adult rat retina. Invest Ophthalmol Vis Sci 41:4268-4274

Nottebohm F (1985): Neuronal replacement in adulthood. Ann N Y Acad Sci 457:143-161

Nottebohm F, Stokes TM, Leonard CM (1976): Central control of song in the canary Serinus canarius. J Comp Neurol 165:457-486

Palmer TD, Markakis EA, Willhoite AR, Safar F, Gage FH (1999): Fibroblast growth factor-2 activates a latent neu- 
rogenic program in neural stem cells from diverse regions of the adult CNS. J Neurosci 19:8487-8497

Palmer TD, Ray J, Gage FH (1995): FGF-2-responsive neuronal progenitors reside in proliferative and quiescent regions of the adult rodent brain. Mol Cell Neurosci 6:474-486

Parent JM, Janumpalli S, McNamara JO, Lowenstein D. H (1998): Increased dentate granule cell neurogenesis following amygdala kindling in the adult rat. Neurosci Lett 247:9-12

Parent JM, Yu TW, Leibowitz RT, Geschwind DH, Sloviter RS, Lowenstein DH (1997): Dentate granule cell neurogenesis is increased by seizures and contributes to aberrant network reorganization in the adult rat hippocampus. J Neurosci 17:3727-3738

Pincus DW, Keyoung HM, Harrison-Restelli C, Goodman RR, Fraser RA, Edgar M, Sakakibara S, Okano H, Nedergaard M, Goldman SA (1998): Fibroblast growth factor-2/ brain-derived neurotrophic factor-associated maturation of new neurons generated from adult human subependymal cells. Ann Neurol 43:576-585

Pixley SK, Dangoria NS, Odoms KK, Hastings L (1998): Effects of insulin-like growth factor 1 on olfactory neurogenesis in vivo and in vitro. Ann $\mathrm{N}$ Y Acad Sci 855:244-247

Pollard H, Charriaut-Marlangue C, Cantagrel S, Represa A, Robain O, Moreau J, Ben-Ari Y (1994): Kainate-induced apoptotic cell death in hippocampal neurons. Neuroscience $63: 7-18$

Ramón y Cajal S (1913-1914): Degeneration and Regeneration in the Nervous System. Madrid

Represa A, Niquet J, Pollard H, Ben-Ari Y (1995): Cell death, gliosis, and synaptic remodeling in the hippocampus of epileptic rats. J Neurobiol 26:413-425

Reynolds BA, Weiss S (1992): Generation of neurons and astrocytes from isolated cells of the adult mammalian central nervous system. Science 255:1707-1710

Richards LJ, Kilpatrick TJ, Bartlett PF (1992): De novo generation of neuronal cells from the adult mouse brain. Proc Natl Acad Sci USA 89:8591-8595

Rousselot P, Lois C, Alvarez-Buylla A (1995): Embryonic (PSA) N-CAM reveals chains of migrating neuroblasts between the lateral ventricle and the olfactory bulb of adult mice. J Comp Neurol 351:51-61

Roy NS, Wang S, Jiang L, Kang J, Benraiss A, Harrison-Restelli C, Fraser RA, Couldwell WT, Kawaguchi A, Okano H, Nedergaard M, Goldman SA (2000): In vitro neurogenesis by progenitor cells isolated from the adult human hippocampus [see comments]. Nat Med 6:271-277

Samanen DW, Forbes WB (1984): Replication and differentiation of olfactory receptor neurons following axotomy in the adult hamster: a morphometric analysis of postnatal neurogenesis. J Comp Neurol 225:201-211

Scharff C, Kirn JR, Grossman M, Macklis JD, Nottebohm F (2000): Targeted neuronal death affects neuronal replacement and vocal behavior in adult songbirds. [see comments]. Neuron 25:481-492

Sheen VL, Macklis JD (1994): Apoptotic mechanisms in targeted neuronal cell death by chromophore-activated photolysis. Exp Neurol 130:67-81
Sheen VL, Macklis JD (1995): Targeted neocortical cell death in adult mice guides migration and differentiation of transplanted embryonic neurons. J Neurosci 15:8378-8392

Sheen VL, Dreyer EB, Macklis JD (1992): Calcium-mediated neuronal degeneration following singlet oxygen production. NeuroReport 3:705-708

Shihabuddin LS, Ray J, Gage FH (1997): FGF-2 is sufficient to isolate progenitors found in the adult mammalian spinal cord. Exp Neurol 148:577-586

Shin JJ, Fricker-Gates RA, Perez FA, Leavitt BR, Zurakowski D, Macklis JD (2000): Transplanted neuroblasts differentiate appropriately into projection neurons with correct neurotransmitter and receptor phenotype in neocortex undergoing targeted projection neuron degeneration. J Neurosci (Online) 20:7404-7416

Shors TJ, Miesegas G, Beylin A, Zhao M, Rydel T, Gould E (2001): Neurogenesis in the adult is involved in the formation of trace memories. Nature 410:372-376

Simpson HB, Vicario DS (1990): Brain pathways for learned and unlearned vocalizations differ in zebra finches. J Neurosci 10:1541-1556

Snyder EY, Yoon C, Flax JD, Macklis JD (1997): Multipotent neural precursors can differentiate toward replacement of neurons undergoing targeted apoptotic degeneration in adult mouse neocortex. Proc Natl Acad Sci USA 94: 11663-11668

Stanfield BB, Trice JE (1988): Evidence that granule cells generated in the dentate gyrus of adult rats extend axonal projections. Exp Brain Res 72:399-406

Suhonen JO, Peterson DA, Ray J, Gage FH (1996): Differentiation of adult hippocampus-derived progenitors into olfactory neurons in vivo. Nature 383:624-627

Szele FG, Chesselet MF (1996): Cortical lesions induce an increase in cell number and PSA-NCAM expression in the subventricular zone of adult rats. J Comp Neurol 368:439-454

Tanapat P, Galea LA, Gould E (1998): Stress inhibits the proliferation of granule cell precursors in the developing dentate gyrus. Int J Dev Neurosci 16:235-239

Trejo JL, Carro E, Torres-Aleman I (2001): Circulating insulin-like growth factor I mediates exercise-induced increases in the number on new neurons in the adult hippocampus. J Neurosci 21:1628-1634

Tropepe V, Coles BL, Chiasson BJ, Horsford DJ, Elia AJ, McInnes RR, van der Kooy D (2000): Retinal stem cells in the adult mammalian eye. Science 287:2032-2036

van Praag H, Christie BR, Sejnowski TJ, Gage FH (1999a): Running enhances neurogenesis, learning, and longterm potentiation in mice. Proc Natl Acad Sci USA 96: 13427-13431

van Praag H, Kempermann G, Gage FH (1999b): Running increases cell proliferation and neurogenesis in the adult mouse dentate gyrus [see comments]. Nat Neurosci 2:266-270

Vescovi AL, Reynolds BA, Fraser DD, Weiss S (1993): bFGF regulates the proliferative fate of unipotent (neuronal) and bipotent (neuronal/astroglial) EGF-generated CNS progenitor cells. Neuron 11:951-966

Wagner JP, Black IB, DiCicco-Bloom E (1999): Stimulation of neonatal and adult brain neurogenesis by subcutaneous 
injection of basic fibroblast growth factor. J Neurosci 19:6006-6016

Wang Y, Sheen VL, Macklis JD (1998): Cortical interneurons upregulate neurotrophins in vivo in response to targeted apoptotic degeneration of neighboring pyramidal neurons. Exp Neurol 154:389-402

Weiss S, Dunne C, Hewson J, Wohl C, Wheatley M, Peterson AC, Reynolds BA (1996): Multipotent CNS stem cells are present in the adult mammalian spinal cord and ventricular neuroaxis. J Neurosci 16:7599-7609

Whittemore SR, Morassutti DJ, Walters WM, Liu RH, Magnuson DS (1999): Mitogen and substrate differentially affect the lineage restriction of adult rat subventricular zone neural precursor cell populations. Exp Cell Res 252:75-95

Whittington DL, Woodruff ML, Baisden RH (1989): The timecourse of trimethyltin-induced fiber and terminal degeneration in hippocampus. Neurotoxicol Teratol 11:21-33

Williams BP, Park JK, Alberta JA, Muhlebach SG, Hwang
GY, Roberts TM, Stiles CD (1997): A PDGF-regulated immediate early gene response initiates neuronal differentiation in ventricular zone progenitor cells. Neuron 18:553-562

Williams H, Crane LA, Hale TK, Esposito MA, Nottebohm F (1992): Right-side dominance for song control in the zebra finch. J Neurobiol 23:1006-1020

Yang Y, Geldmacher DS, Herrup K (2001): DNA replication precedes neuronal cell death in alzheimer's disease. J Neurosci 21:2661-2668

Young MJ, Ray J, Whiteley SJ, Klassen H, Gage FH (2000): Neuronal differentiation and morphological integration of hippocampal progenitor cells transplanted to the retina of immature and mature dystrophic rats. Mol Cell Neurosci 16:197-205

Zigova T, Pencea V, Wiegand SJ, Luskin MB (1998): Intraventricular administration of BDNF increases the number of newly generated neurons in the adult olfactory bulb. Mol Cell Neurosci 11:234-245 